\title{
WestVirginiaUniversity
}

THE RESEARCH REPOSITORY @ WVU

Graduate Theses, Dissertations, and Problem Reports

2013

\section{Development of Synthetic Pathways for Carbon Nanohoops}

\author{
Yiwei Huang \\ West Virginia University
}

Follow this and additional works at: https://researchrepository.wvu.edu/etd

\section{Recommended Citation}

Huang, Yiwei, "Development of Synthetic Pathways for Carbon Nanohoops" (2013). Graduate Theses, Dissertations, and Problem Reports. 4973.

https://researchrepository.wvu.edu/etd/4973

This Thesis is protected by copyright and/or related rights. It has been brought to you by the The Research Repository @ WVU with permission from the rights-holder(s). You are free to use this Thesis in any way that is permitted by the copyright and related rights legislation that applies to your use. For other uses you must obtain permission from the rights-holder(s) directly, unless additional rights are indicated by a Creative Commons license in the record and/ or on the work itself. This Thesis has been accepted for inclusion in WVU Graduate Theses, Dissertations, and Problem Reports collection by an authorized administrator of The Research Repository @ WVU. For more information, please contact researchrepository@mail.wvu.edu. 


\title{
Development of Synthetic Pathways for Carbon Nanohoops
}

\author{
Yiwei Huang
}

Thesis submitted to the

Eberly College of Arts and Sciences

at West Virginia University

in partial fulfillment of the requirements

for the degree of

Master of Science

in

Chemistry

\author{
Kung K. Wang, Ph. D., Chair \\ Jeffrey L. Petersen, Ph. D. \\ Björn C. G. Söderberg, Ph. D. \\ C. Eugene Bennett Department of Chemistry \\ Morgantown, West Virginia \\ 2013
}

Keywords: Cycloparaphenylene, Carbon Nanotube, Carbon Nanohoop

Copyright 2013 Yiwei Huang 


\section{ABSTRACT \\ Development of Synthetic Pathways for Carbon Nanohoops \\ Yiwei Huang}

A synthetic pathway was developed for the preparation of a precursor of a [6]cycloparaphenylene derivative, which represents the shortest repeating carbon nanohoop segment of an armchair $(6,6)$ carbon nanotube. As a key intermediate of the synthetic sequence, trans,trans-1,4-di(4-bromophenyl)-1,3-butadiene was synthesized by using the Horner-Wadsworth-Emmons reaction between 4-bromocinnamaldehyde and diethyl 4-bromobenzylphosphonate reported in the literature. The use of $\mathrm{BF}_{3} \cdot \mathrm{OEt}_{2}$ as a Lewis acid for the Lewis acid-catalyzed Diels-Alder reaction between trans,trans-1,4di(4-bromophenyl)-1,3-butadiene and 1,4-benzoquinone was successful in producing cis5,8-di(4-bromophenyl)-5,8-dihydro-1,4-naphthalenediol. The Diels-Alder reaction ensures that the two 4-bromophenyl substituents are cis to each other in the sixmembered ring, which is of critical importance for the subsequent dimerization reaction. Methylation with dimethyl sulfate in the presence of potassium carbonate afforded the corresponding methylated hydroquinone. The nickel(0)-catalyzed homocoupling reactions produced the corresponding dimers as a mixture of diastereomers with the two 1,4-dimethoxyphenyl groups pointing either in the same direction or in the opposite directions. It is envisioned that aromatization of the dimers could then lead to the [6]cycloparaphenylene derivative. 
Dedicated to

my parents 


\section{ACKNOWLEDGEMENT}

I would like to express my sincerest appreciation to my research advisor, Dr. Kung K. Wang, for his guidance, encouragement and support throughout my graduate studies. It is my great pleasure to have an advisor like him, with great patience and knowledge. I'm greatly benefited from learning and discussing chemistry with him.

I would also like to express my gratitude to my research committee members, Dr. Jeffrey L. Petersen and Dr. Björn C. G. Söderberg, for their helpful suggestions and valuable discussions.

My special thanks go to Dr. Jeffrey L. Petersen for his great help with X-ray crystal structure analyses. My special thanks also go to Dr. Novruz G. Akhmedov for his great assistance in NMR studies.

I would also like to thank the former and present group members of our research group, Changfeng Huang, Chi-Yuan Tseng, Doreen Makaya, for their help and support.

I also want to express my deepest gratitude to my parents and my family for their love and support.

Financial supports from the C. Eugene Bennett Department of Chemistry at West Virginia University and the National Science Foundation are gratefully acknowledged. 


\section{TABLE OF CONTENTS}

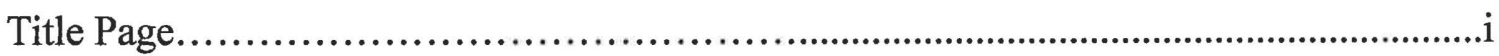

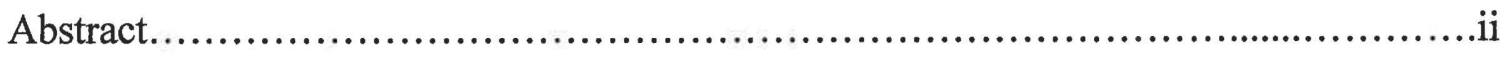

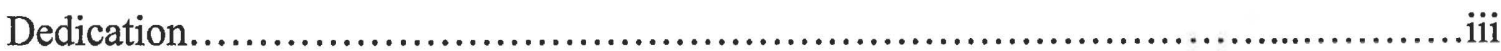

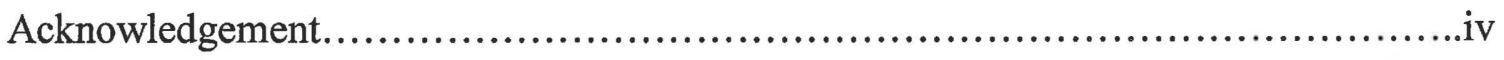

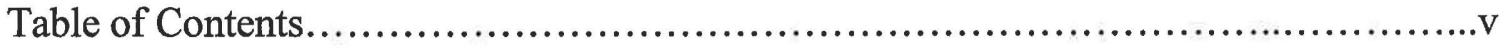

List of Figures.......................................................................

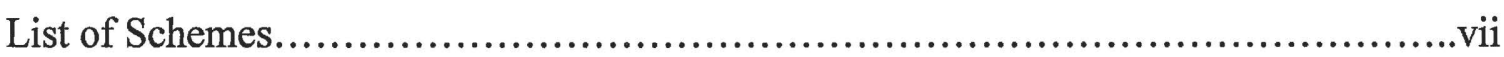

List of ${ }^{1} \mathrm{H}$ and ${ }^{13} \mathrm{C}$ NMR Spectra.....................................................viii

\section{Part I}

\section{Development of Synthetic Pathways for Carbon Nanohoops}

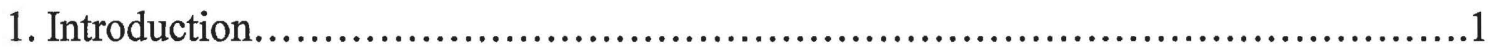

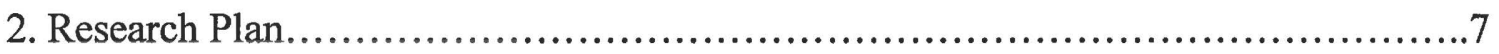

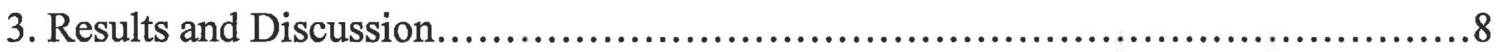

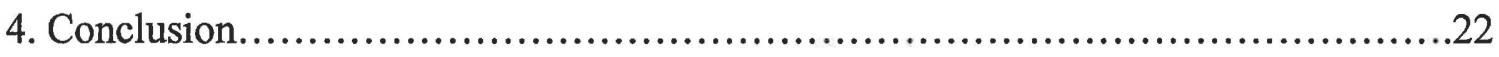

\section{Part II}

\section{Experimental Section}

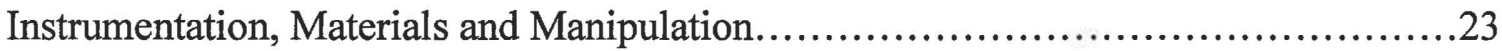

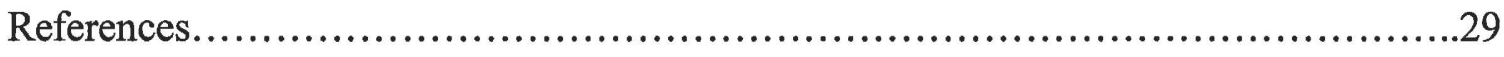

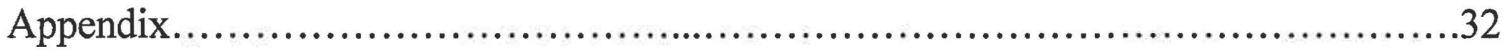




\section{LIST OF FIGURES}

Figure 1. Structures of single-walled armchair $(6,6)$-CNT, armchair $(8,8)$-CNT, zigzag $(9,0)-\mathrm{CNT}$, and zigzag $(12,0)-\mathrm{CNT}$. .1

Figure 2. Structures of [6]cycloparaphenylene and [12]cyclacene $\ldots \ldots \ldots \ldots \ldots \ldots \ldots \ldots \ldots .2$

Figure 3. MM2-optimized structures of dibromides 18a and 18b.....................9 Figure 4. (Left) Perspective view of the molecular structure of $\mathrm{C}_{22} \mathrm{H}_{14} \mathrm{Br}_{2} \mathrm{O}_{2}(40)$ with the atom labeling scheme provided for the non-hydrogen atoms. The thermal ellipsoids are scaled to enclosed $30 \%$ probability. (Right) Perspective view of the molecular structure of $\mathrm{C}_{22} \mathrm{H}_{16} \mathrm{Br}_{2} \mathrm{O}_{2}$ (41) with the atom labeling scheme provided for the non-hydrogen atoms. The thermal ellipsoids are scaled to enclosed $30 \%$ probability .........................18

Figure 5. (Left) Structure of a bis-Diels-Alder adduct 43. (Right) Perspective view of the molecular structure of $\mathrm{C}_{38} \mathrm{H}_{24} \mathrm{Br}_{4} \mathrm{O}_{2}$ (43) with the atom labeling scheme provided for the non-hydrogen atoms. The thermal ellipsoids are scaled to enclosed $30 \%$ probability. 19

Figure 6. Perspective view of the molecular structure of $\mathrm{C}_{24} \mathrm{H}_{20} \mathrm{Br}_{2} \mathrm{O}_{2}(\mathbf{1 8 b})$ with the atom labeling scheme provided for the non-hydrogen atoms. The thermal ellipsoids are scaled to enclosed $30 \%$ probability. 


\section{LIST OF SCHEMES}

Scheme 1. Synthesis of [9]-, [12]-, and [18]cycloparaphenylenes.....................

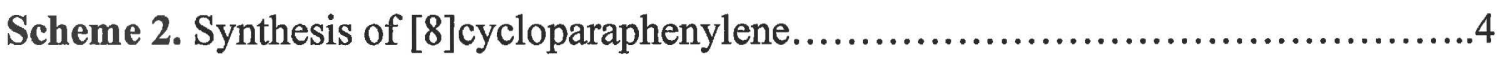

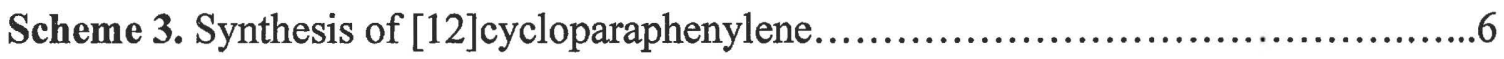

Scheme 4. A proposed synthetic route for the [6]cycloparaphenylene derivative $20 \ldots \ldots . .7$

Scheme 5. A proposed synthetic route for dibromide 18.............................

Scheme 6. Synthesis of trans,trans-1,4-di(4-bromophenyl)-1,3-butadiene (21)...........10

Scheme 7. Synthesis of diene 21 by $\mathrm{ZnCl}_{2}$ - or $\mathrm{CuBr} \mathrm{SMe}_{2}$-promoted reductive coupling

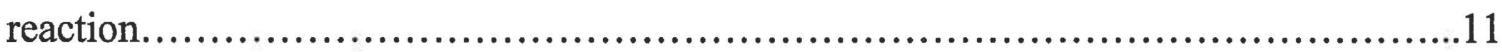

Scheme 8. Synthesis of diene 21 by hydroboration and the Suzuki-Miyaura coupling

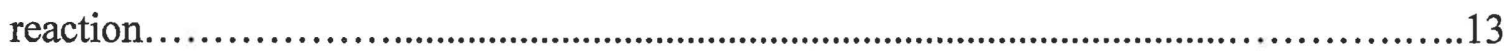

Scheme 9. Formation of benzynes for the Diels-Alder reactions with diene 21...........16

Scheme 10. $\mathrm{BF}_{3} \cdot \mathrm{OEt}_{2}$ catalyzed Diels-Alder reaction...............................17

Scheme 11. Synthesis of dibromide 18b and the [6]CPP derivative precursor $19 \mathrm{~b}$ from

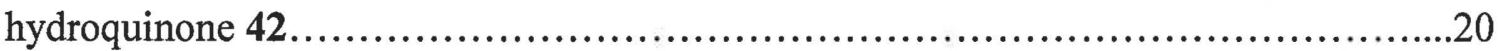




\section{LIST OF ${ }^{1} \mathrm{H}$ AND ${ }^{13} \mathrm{C}$ NMR SPECTRA}

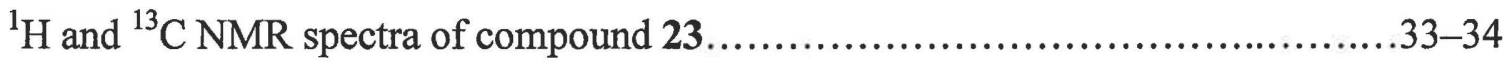

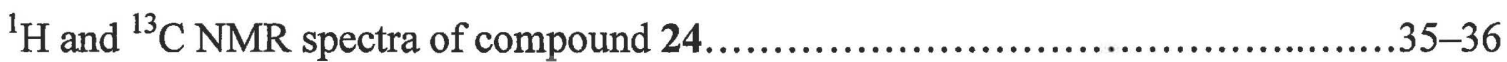

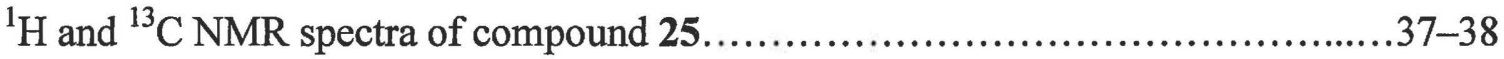

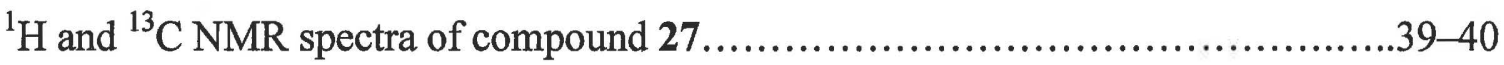

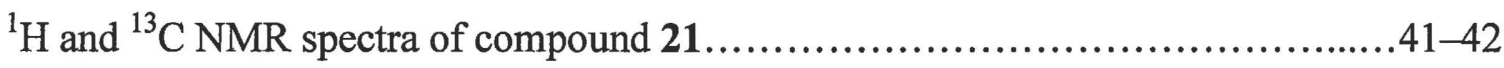

${ }^{1} \mathrm{H}$ and ${ }^{13} \mathrm{C}$ NMR spectra of compound 18a.....................................43-44

${ }^{1} \mathrm{H}$ and ${ }^{13} \mathrm{C}$ NMR spectra of compound 43.......................................45-46

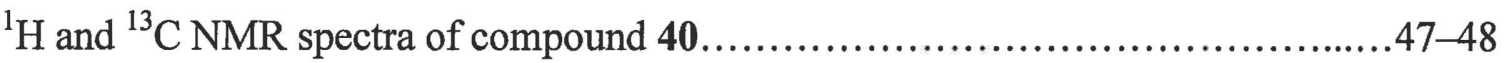

${ }^{1} \mathrm{H}$ and ${ }^{13} \mathrm{C}$ NMR spectra of compound 41 .....................................49-50

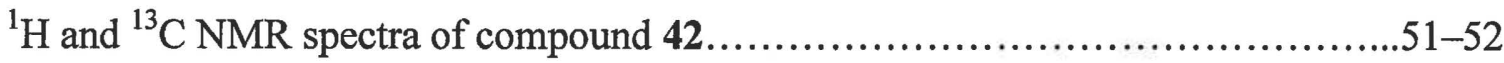

${ }^{1} \mathrm{H}$ and ${ }^{13} \mathrm{C}$ NMR spectra of compound 18b.....................................53-54

${ }^{1} \mathrm{H}$ and ${ }^{13} \mathrm{C}$ NMR spectra of compound 19b......................................55-56 


\section{Part I}

\section{Development of Synthetic Pathways for Carbon Nanohoops}

\section{Introduction}

Carbon nanotubes (CNTs) are cylindrical nanostructures comprised of carbon atoms. They are allotropes of carbon. Carbon nanotubes were first discovered in 1952 by L. V. Radushkevich and V. M. Lukyanovich. ${ }^{1}$ Since the discovery, several methods for the synthesis of carbon nanotubes have been developed, including arc discharge, laser ablation, chemical vapor deposition, flame pyrolysis, and bottom-up organic synthesis approach. $^{2}$

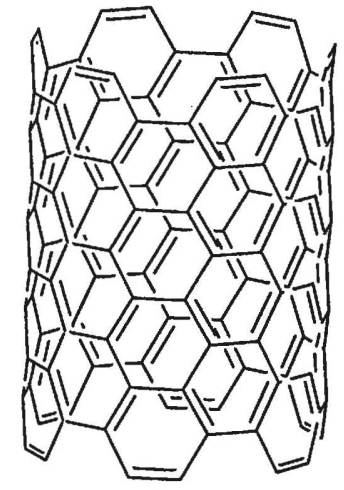

armchair $(6,6)$-CNT

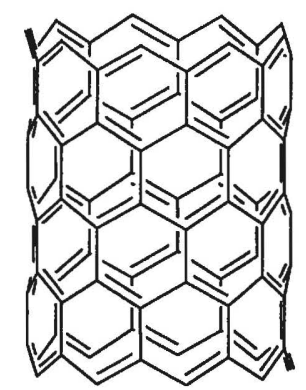

zigzag $(9,0)-$ CNT

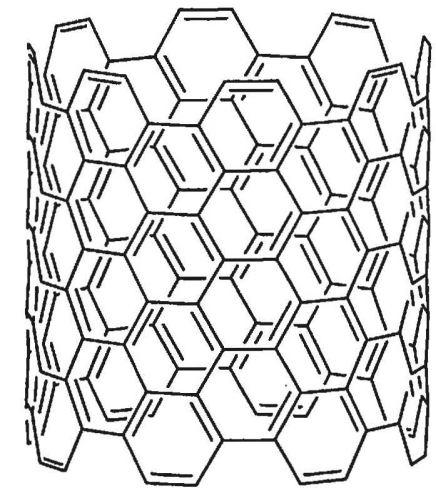

armchair (8,8)-CNT

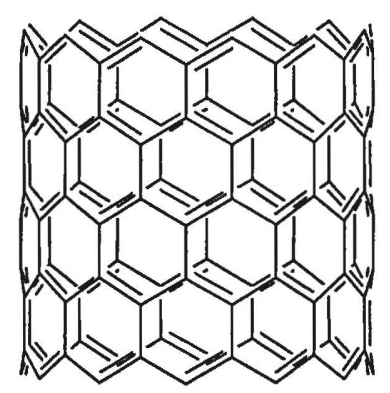

zigzag (12,0)-CNT

Figure 1. Structures of single-walled armchair $(6,6)-\mathrm{CNT}$, armchair $(8,8)-\mathrm{CNT}$, zigzag $(9,0)-\mathrm{CNT}$, and zigzag $(12,0)-\mathrm{CNT}$. 
There are three general types of single-walled carbon nanotubes: armchair, zigzag, and chiral. Typical examples of armchair and zigzag single-walled carbon nanotubes are given in Figure 1.

For armchair carbon nanotubes, [n]cycloparaphenylenes represent the shortest segments of the repeating units. In the cases of zigzag carbon nanotubes, [n]cyclacenes are the shortest repeating units. The structures of [6]cycloparaphenylene and [12]cyclacene, representing the shortest segment of armchair (6,6)-CNT and zigzag $(12,0)$-CNT, respectively, are depicted in Figure 2. The structure of [6]cycloparaphenylene is constructed by para connections of six benzene rings whereas the structure of [12]cyclacene is formed by side-by-side fusing of 12 benzene rings. Several representative [n]cycloparaphenylenes have been synthesized. However, because of the reactive nature of the extended acene derivatives, [n]cyclacenes have not yet been synthesized.

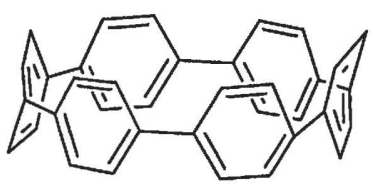

[6]cycloparaphenylene

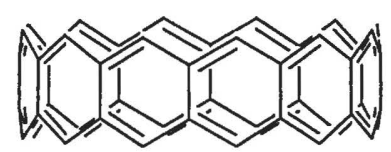

[12]cyclacene

Figure 2. Structures of [6]cycloparaphenylene and [12]cyclacene.

The first synthesis of cycloparaphenylenes was reported by Bertozzi, Jasti and coworkers in 2008 (Scheme 1). ${ }^{3}$ The first step of the synthetic sequence was monolithiation of 1,4-diiodobenzene with $n$ - $\mathrm{BuLi}$ at $-78{ }^{\circ} \mathrm{C}$, followed by addition of $p$-benzoquinone to generate a syn-diol. The diol was alkylated using methyl iodide to form diiodide 1 . 
Transformation of diiodide 1 to diboronate $\mathbf{2}$ followed by the Suzuki-Miyaura coupling reaction with diiodide 1 produced a mixture of macrocycles 3,4 and 5 . Each macrocycle was then treated with lithium napthalenide, leading to the corresponding [9]cycloparaphenylene 6, [12]cycloparaphenylene 7, and [18]cycloparaphenylene 8 , respectively. Recently, this general synthetic strategy was extended to the synthesis of [6]cycloparaphenylene.
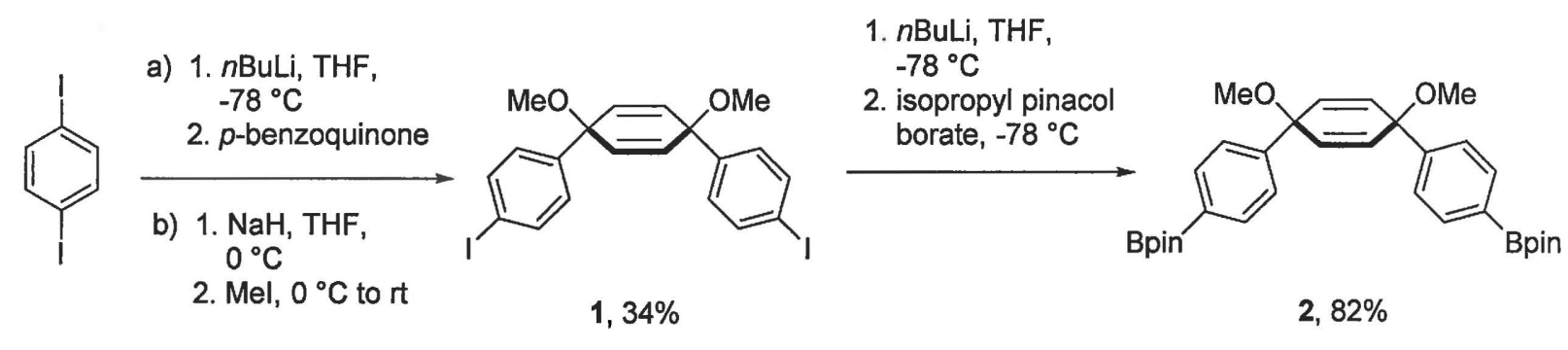

$2,82 \%$

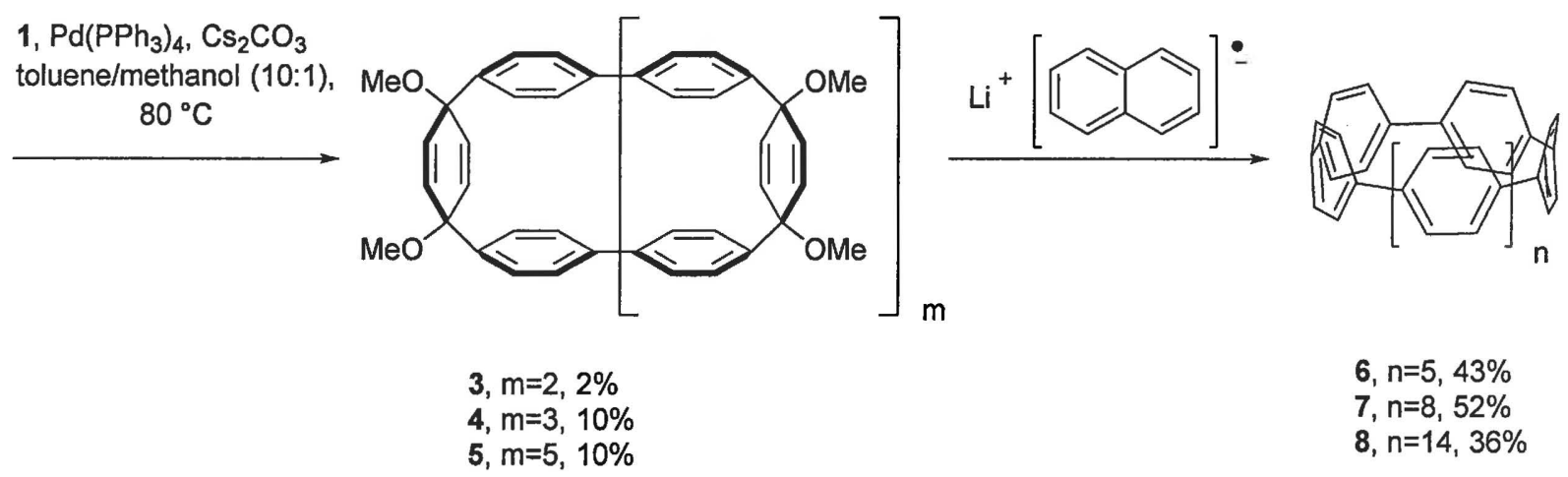

Scheme 1. Synthesis of [9]-, [12]-, and [18]cycloparaphenylenes.

Yamago and co-workers reported a synthesis of [8]cycloparaphenylene from a square-shaped tetranuclear platinum complex in 2010 (Scheme 2). ${ }^{4}$ 4,4'Bis(trimethylstannyl)biphenyl (9) was used as the starting material in this case. It was treated with one equivalent of $\mathrm{PtCl}_{2}(\mathrm{COD})$ in THF under reflux for 35 hours, affording 
the square-shaped platinum complex 10 in 57\% yield. This platinum complex 10 was then treated with four equivalents of $1,1^{\prime}$-bis(diphenylphosphino)ferrocene in dichloromethane at room temperature for 20 hours, producing the square-shaped platinum complex 11 in $91 \%$ yield. Reductive elimination reaction was then carried out by treating platinum complex 11 with seven equivalents of bromine in toluene at $95{ }^{\circ} \mathrm{C}$ for 17 hours, producing [8]cycloparaphenylene 12 in $49 \%$ yield. It was the smallest CPP at that time.

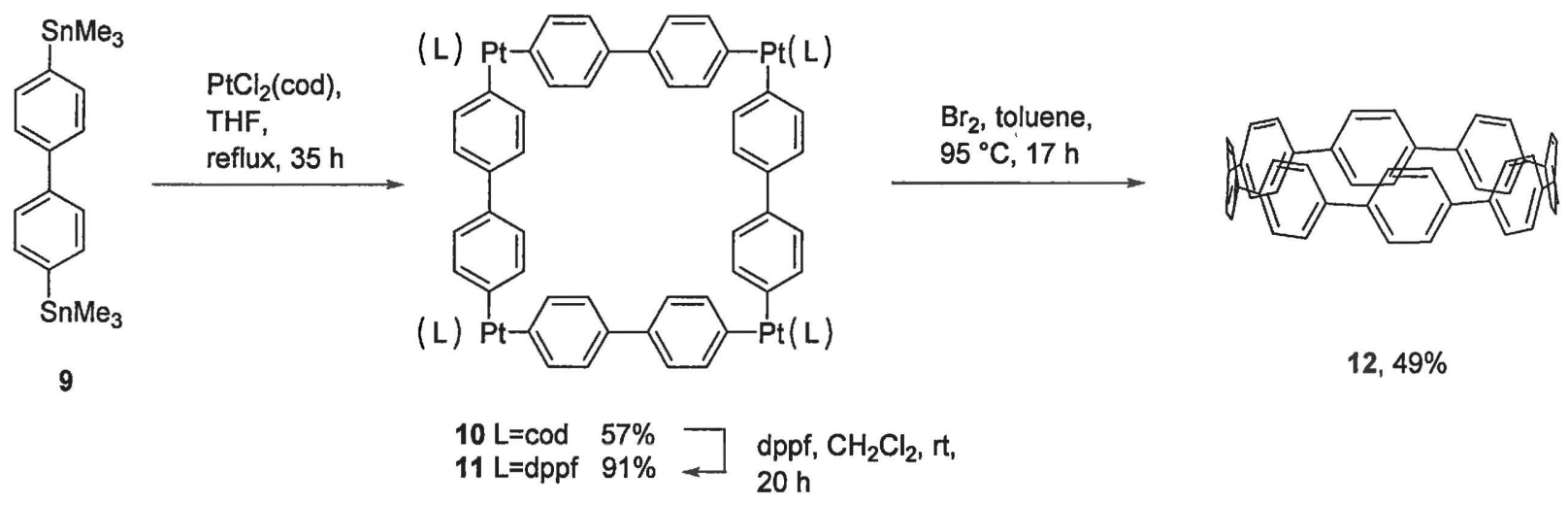

Scheme 2. Synthesis of [8]cycloparaphenylene.

Itami and co-workers reported a selective synthesis of [12]cycloparaphenylene in 2009 (Scheme 3). ${ }^{5}$ In this synthesis route, 1,4-diiodobenzene was first treated with $n$ BuLi at $-78{ }^{\circ} \mathrm{C}$ for monolithiation to form 4-iodophenyllithium, followed by the addition of 1,4-cyclohexanedione. The cis-isomer $\mathbf{1 3}$ was produced as the major product (cis:trans $=81: 19)$ in $48 \%$ yield. The cis-diol $\mathbf{1 3}$ has an L-shaped structure. The cis-diol 13 was 
then converted to the methoxymethyl (MOM)-protected diiodide 14 in $98 \%$ yield and diboronate 15 in $81 \%$ yield. Suzuki-Miyaura coupling between diiodide 14 and diboronate 15 afforded the trimer 16 in $81 \%$ yield. Trimer diiodide 16 was then coupled with diboronate 15 again to form the cyclic tetramer 17. Microwave assisted aromatization reaction occurred when tetramer 17 was treated with $p$-toluenesulfonic acid in $m$-xylene at $150{ }^{\circ} \mathrm{C}$ for 30 minutes, producing [12]cycloparaphenylene 7 in $62 \%$ yield. Several other cycloparaphenylenes were likewise synthesized. 


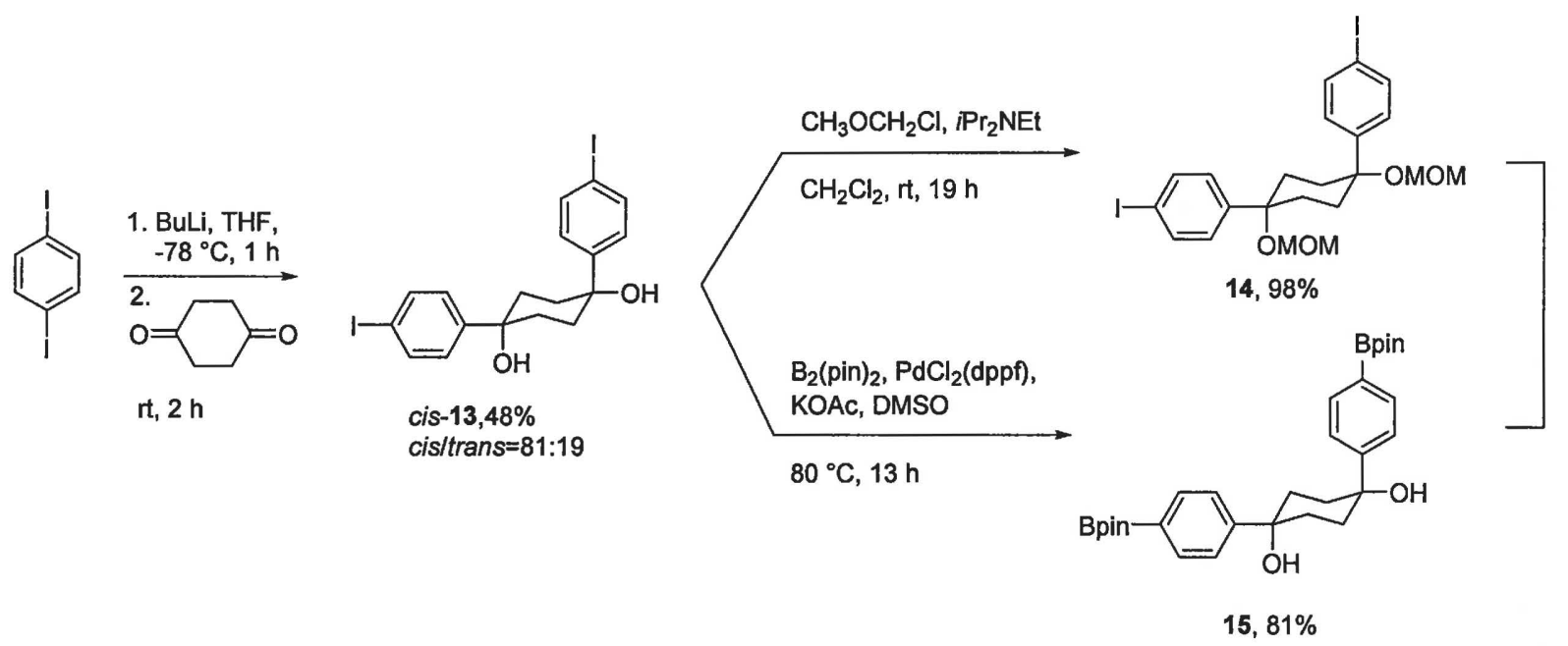

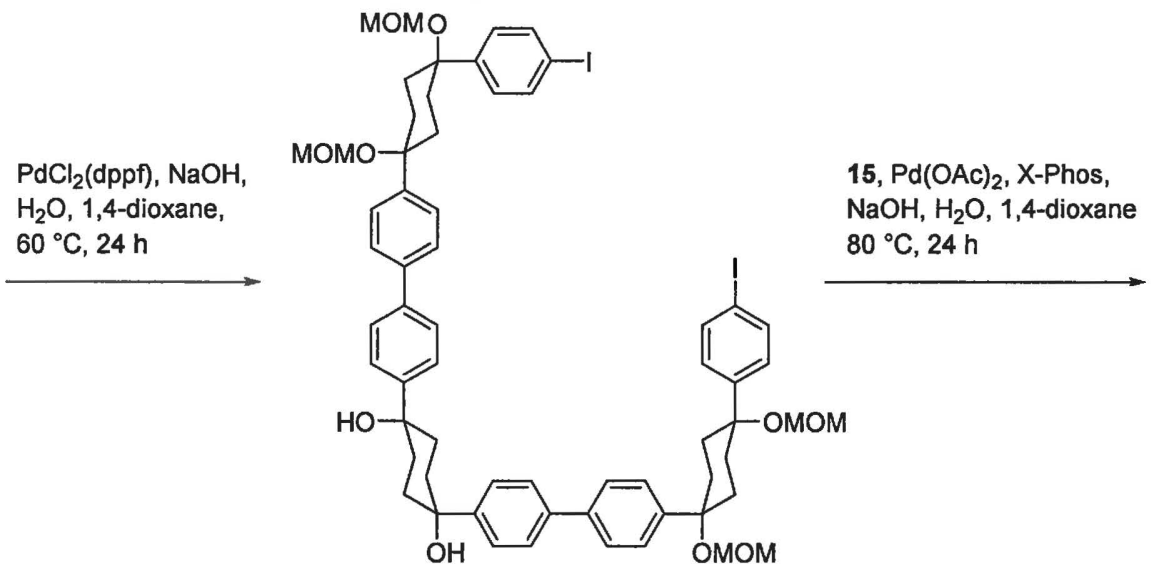

$16,81 \%$

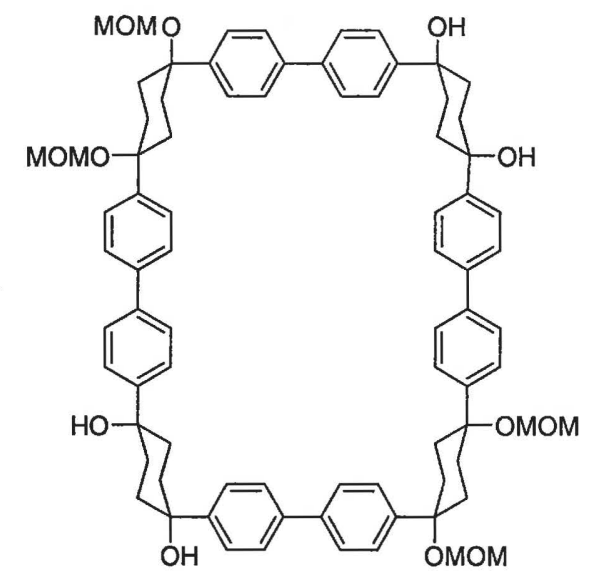

$17,51 \%$
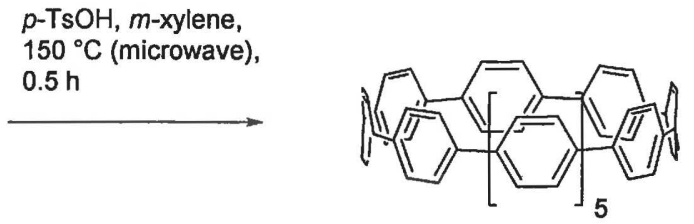

$7,62 \%$

Scheme 3. Synthesis of [12]cycloparaphenylene.

So far, synthesis of [6]-, [7]- ,[8]-, [9]-, [10]-, [11]-, [12]-, [13]-, [14]-, [15]-, [16]-, and [18]cycloparaphenylene have been reported. ${ }^{3-13}$ Also, some cycloparaphenylene derivatives have been successfully synthesized. ${ }^{14-18}$ 


\section{Research Plan}

Our research goal is to develop a new synthetic pathway to the [6]cycloparaphenylene ([6]CPP) derivative 20. To achieve this goal, we plan to use the synthetic sequence outlined in Scheme 4 for its preparation.

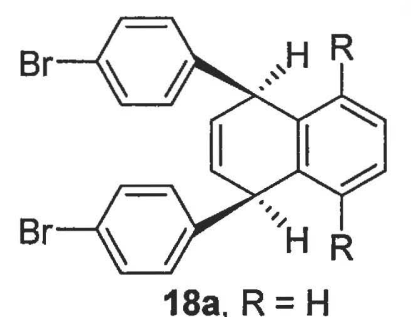

$18 \mathrm{~b}, \mathrm{R}=\mathrm{MeO}$

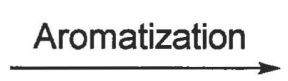

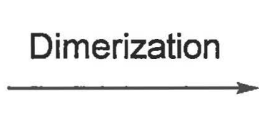<smiles>[R]c1ccc([R])c2c1CC=CC2c1ccc(-c2ccc(-c3ccc(C4C=CC([R])c5c([R])ccc([R])c54)cc3)cc2)cc1</smiles>

19

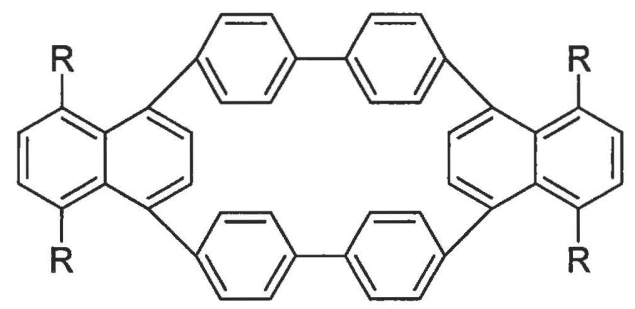

20

Scheme 4. A proposed synthetic route for the [6]cycloparaphenylene derivative 20.

The precursor 18 is to be prepared by the Diels-Alder reaction between trans, trans-1,4-di(4-bromophenyl)-1,3-butadiene (21) and a suitable dienophile, such as benzyne or $p$-benzoquinone (Scheme 5).

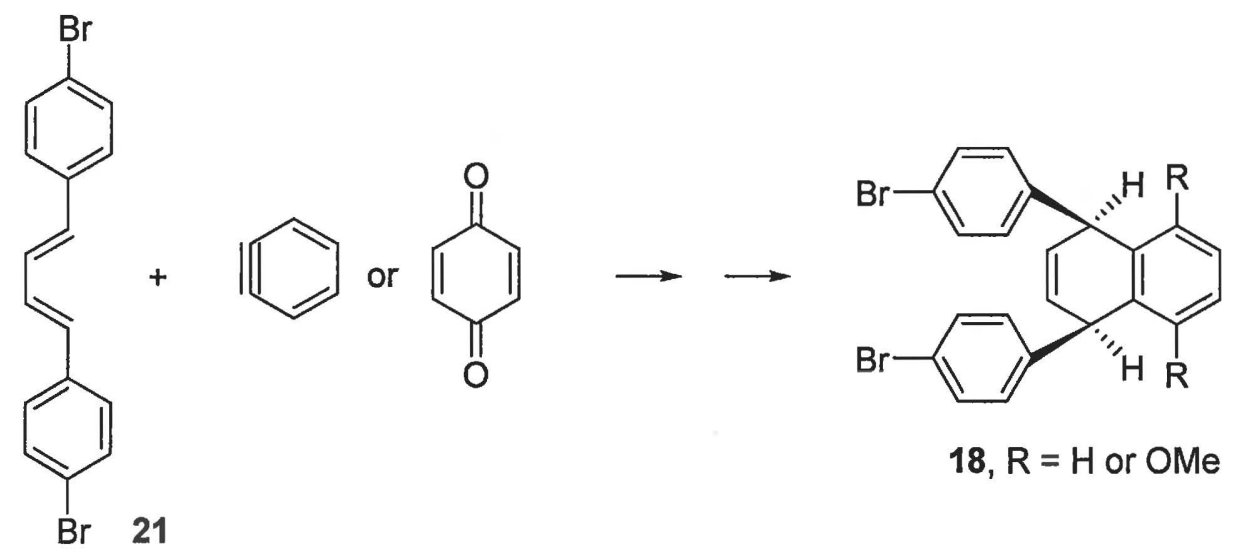

Scheme 5. A proposed synthetic route for dibromide 18. 


\section{Results and Discussion}

Compound $\mathbf{1 8}$ is a key intermediate in the design for the synthesis of the [6]cycloparaphenylene derivative 20. In the structure of dibromide 18, the two hydrogen atoms on the six-membered ring are cis to each other. As a result, the two bromosubstituted phenyl rings are cis to each other as well. In addition, the two R groups on the benzene ring could also play a very significant role. With the presence of 1,3 -allylic strains, the two bromo-substituted phenyl rings would be close to being parallel to each other, which would be very helpful in directing the following coupling reactions toward the formation of a dimer because of the reduced ring strain in the [6]cycloparaphenylene precursor 19.

The MM2-optimized structure of 18a $(\mathrm{R}=\mathrm{H})$ depicted in Figure 3 indicates that the two 4-bromophenyl substituents are oriented not parallel to each other. On the other hand, the MM2-optimized structure of $18 \mathrm{~b}(\mathrm{R}=\mathrm{MeO})$ showed that the two 4bromophenyl substituents are close to being parallel to each other. The parallel orientation of the two 4-bromophenyl substituents in $\mathbf{1 8 b}$ minimizes the 1,3-allylic strain arising from the steric interactions between the methoxy group and its neighboring 4bromophenyl group.

In most of the reported cycloparaphenylene syntheses, the greatest challenge is to overcome the enormous strain energy in the bent aromatic systems, which leads to very low yields of cycloparaphenylenes of small ring sizes, formation of a variety of large size cycloparaphenylenes, and a combination of these two problems. The parallel orientations of the two 4-bromophenyl substituents in $\mathbf{1 8 b}$ could greatly minimize the ring strains. As a result, the subsequent coupling reaction could favor the formation of the dimer 19, 
leading to the [6]cycloparaphenylene derivative $\mathbf{2 0}$ containing only six benzene units in the cyclic system.<smiles>CC(C)(C)[Na]</smiles><smiles>[CH][C@@H]1C=C[C@@H](C(c2ccc(Br)cc2)c2ccc(Br)cc2)c2c(OC)ccc(OC)c21</smiles>
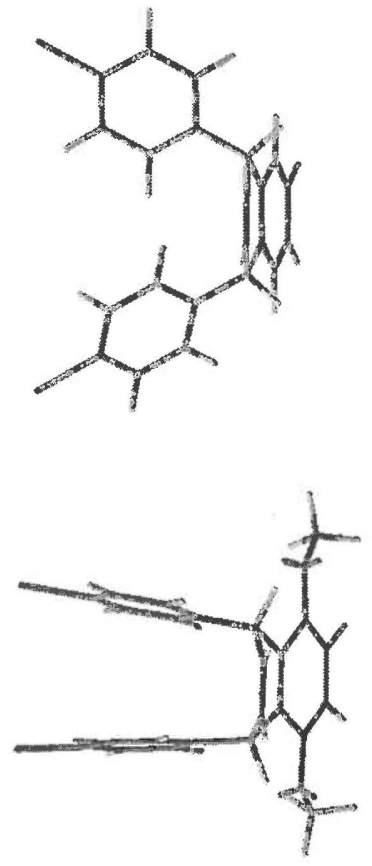

Figure 3. MM2-optimized structures of dibromides 18a and 18b.

As it was mentioned early, the two 4-bromophenyl substituents in $\mathbf{1 8 b}$ are cis to each other. This cis relationship could be achieved by the Diels-Alder reaction between dibromide 21 and $p$-benzoquinone as outlined in Scheme 5. Dibromide 21 was previously synthesized by the Horner-Wadsworth-Emmons reaction between 25 and 27 as outlined in Scheme $6{ }^{19}$ The synthetic sequence outlined in Scheme 6 was carried out, and several grams of trans,trans-1,4-di(4-bromophenyl)-1,3-butadiene(21) were obtained. 
<smiles>COC(=O)/C=C/c1ccc(Br)cc1</smiles>

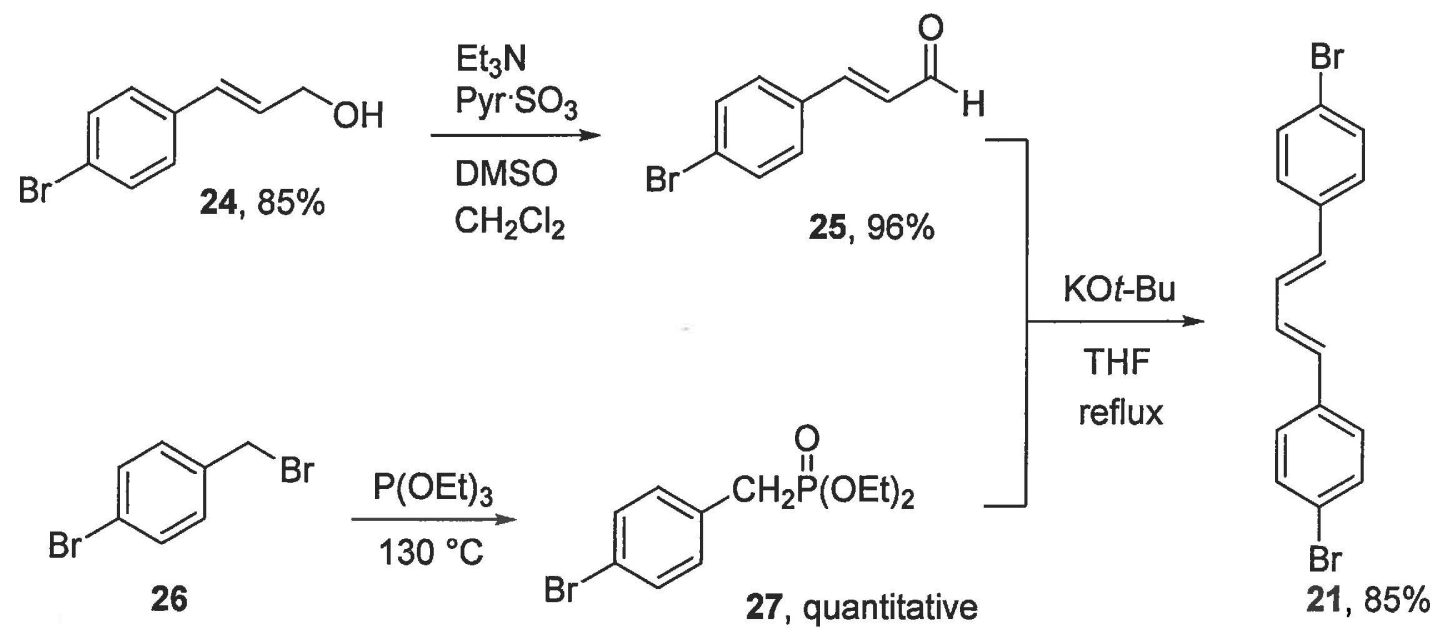

Scheme 6. Synthesis of trans,trans-1,4-di(4-bromophenyl)-1,3-butadiene (21).

In addition, two new synthetic methods for the preparation of dienes were explored in order to provide flexibility for introducing other functionalities on the diene. The first method was outlined in Scheme 7, and phenylacetylene was used in the model study. Dicyclohexylborane(28) was obtained from hydroboration of cyclohexene using one-half equivalent of borane-dimethyl sulfide complex, ${ }^{20}$ which then served as a hydroborating reagent for the second hydroboration reaction with phenylacetylene to produce $(E)$-alkenyldicyclohexylborane $29 a .^{21}$ Borane $29 a$ was transferred into a suspension of $\mathrm{NaOCH}_{3}$ in THF at room temperature to form the ate complex 30, which was then transferred into one-half equivalent of zinc chloride solution in $\mathrm{THF}^{22}$ or a suspension of one equivalent of copper(I) bromide-dimethyl sulfide complex in $\mathrm{THF}^{23}$, to form the trans,trans-1,4-diphenyl-1,3-butadiene 31. However, the model study using 
phenylacetylene as the starting material produced only low yields of diene $\mathbf{3 1}$ presumably because of small scales of the reaction.

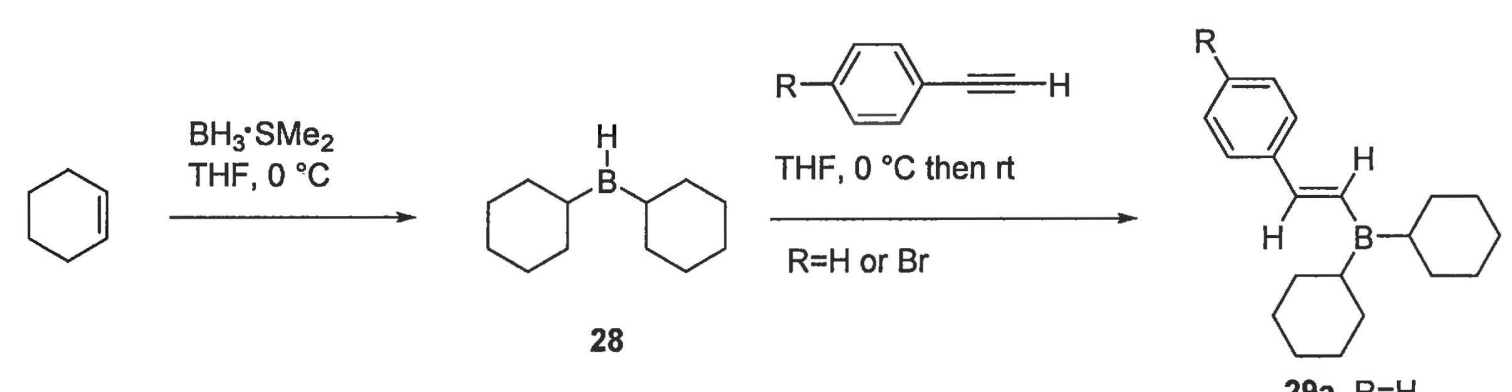

$29 \mathrm{~b}, \mathrm{R}=\mathrm{Br}$

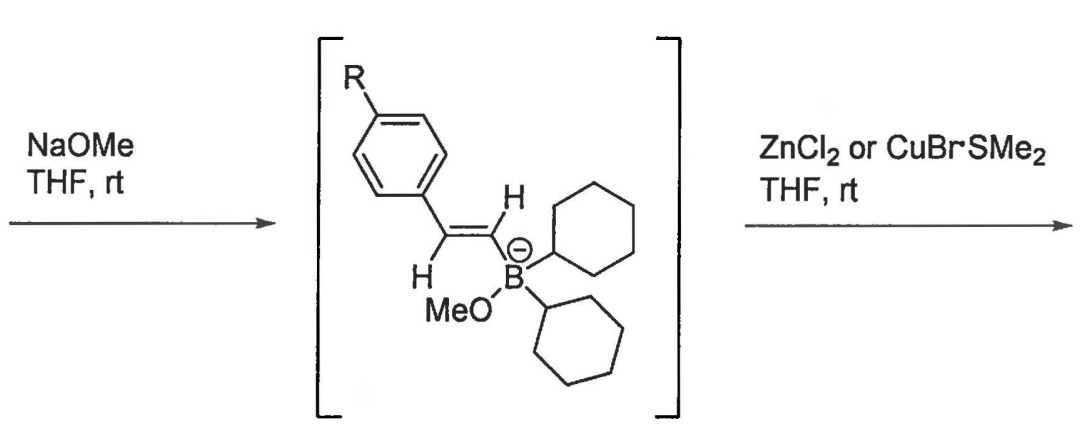

30<smiles>[R]c1ccc(/C=C/C=C/c2ccc([R])cc2)cc1</smiles>

$31, \mathrm{R}=\mathrm{H}$ $21, \mathrm{R}=\mathrm{Br}$

Scheme 7. Synthesis of diene 21 by $\mathrm{ZnCl}_{2}$ - or $\mathrm{CuBr} \mathrm{SMe}_{2}$-promoted reductive coupling reaction.

The second method which combined the hydroboration reaction and the SuzukiMiyaura coupling reaction was shown in Scheme 8. The starting material 4bromophenylacetylene $\mathbf{3 3}$ was obtained through the Sonogashira coupling reaction between 1-bromo-4-iodobenzene and (trimethylsilyl)acetylene, which produced (4bromophenyl)ethynyltrimethylsilane 32, followed by desilylation with the treatment of aqueous sodium hydroxide solution in a mixture of diethyl ether and methanol. Hydroboration of phenylacetylene and 4-bromophenylacetylene 33 with catecholborane 
at $70^{\circ} \mathrm{C}$ produced the corresponding 2-(E-alkenyl)-1,3,2-benzodioxaboroles 34a and $34 \mathbf{b}$, respectively. Hydrolysis of $34 \mathbf{a}$ and $34 \mathbf{b}$ at $70{ }^{\circ} \mathrm{C}$ afforded the corresponding alkenylboronic acids $35 \mathrm{a}$ and $35 \mathrm{~b}$, respectively. Treatment of boronic acids $35 \mathrm{a}$ and $\mathbf{3 5 b}$ with iodine in diethyl ether in the presence of sodium hydroxide afforded alkenyl iodides 36a and 36b, respectively. ${ }^{20,24}$ The following Suzuki-Miyaura coupling reaction between 36a and 34a produced diene 31. Similarly, diene 21 could be produced from coupling between 34b and $\mathbf{3 6} \mathbf{b} .{ }^{25}$ However, in the case of 4-bromophenylacetylene 33, the overall yield of corresponding alkenyl iodide $\mathbf{3 6} \mathbf{b}$ was very low, so this method was not further used to synthesize diene $\mathbf{2 1}$ in this research project. Nevertheless a success of this method could be very useful for the synthesis of other dienes to further enhance the versatility of this research project in the future. 

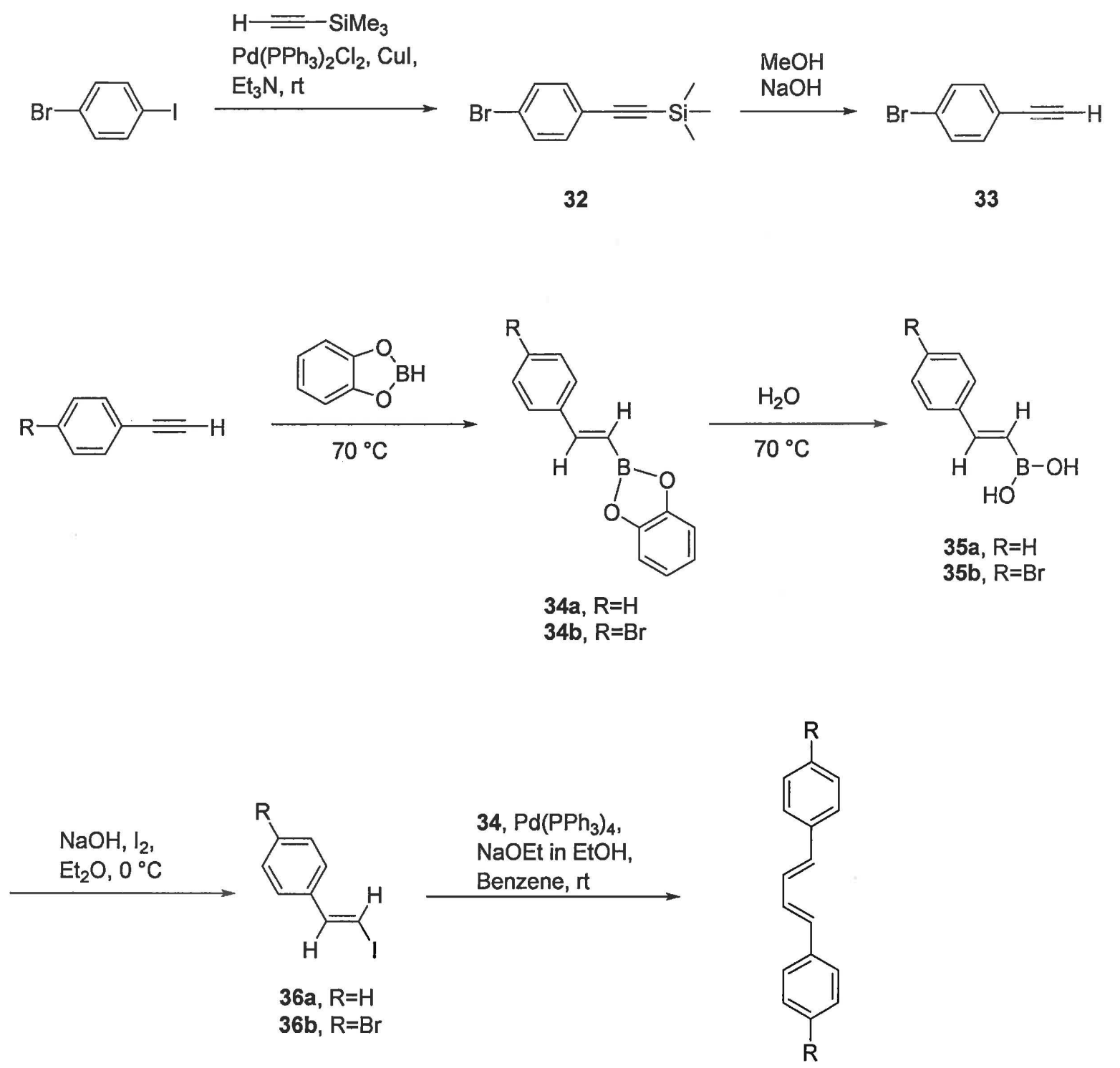

$$
\begin{aligned}
& 31, R=H \\
& 21, R=B r
\end{aligned}
$$

Scheme 8. Synthesis of diene 21 by hydroboration and the Suzuki-Miyaura coupling reaction.

With 21 in hand, the Diels-Alder reaction between 21 and $p$-benzoquinone was investigated. Several conditions were used, including (a) heating at $75^{\circ} \mathrm{C}$ in benzene, (b) heating at $95{ }^{\circ} \mathrm{C}$ in benzene, (c) heating at $138{ }^{\circ} \mathrm{C}$ in $p$-xylene, (d) heating at $55^{\circ} \mathrm{C}$ in 
glacial acetic acid, (e) room temperature in glacial acetic acid, (f) room temperature in a mixture of solvent of glacial acetic acid and ethanol in the presence of hydroquinone, and (g) heating at $65{ }^{\circ} \mathrm{C}$ in a mixture of solvent of glacial acetic acid and ethanol in the presence of hydroquinone. ${ }^{26-30}$ However, none of these conditions worked.

So we decided to investigate the Diels-Alder reaction of diene 21 with a more reactive dienophile, benzyne. The method of using a fluoride to induce the 1,2elimination of TMS and OTf groups to generate benzyne for the Diels-Alder reaction with diene 21 was investigated, as shown in Scheme 9. Three triflates, 2(trimethylsilyl)phenyl trifluoromethanesulfonate $\quad$ (37a), 3-methoxy-2(trimethylsilyl)phenyl trifluoromethanesulfonate (37b) and 3,6-dimethoxy-2(trimethylsilyl)phenyl trifluoromethanesulfonate (37c) were used. The Diels-Alder reaction between diene 21 and triflate 37a was carried out first. In the initial experiment, 3 equivalents of triflate $37 \mathbf{a}$ was added in one portion to a mixture of diene 21 and cesium fluoride (6 equiv) in acetonitrile, and the reaction mixture was stirred under a nitrogen atmosphere at room temperature for 18 hours. After 18 hours, all of the diene were consumed, and the desired DA adduct 18a was formed. The structure of 18a was elucidated by ${ }^{1} \mathrm{H}$ NMR with the appearance of two distinct peaks from the benzylic protons at $\delta 4.69$ and the alkenyl protons at $\delta 5.91$. However, in addition to the desired DA adduct 18a, a substantial amount of byproducts was formed. In order to avoid the formation of byproducts, the amount of triflate $37 \mathbf{a}$ was decreased to 1.5 equivalents and 3 equivalents of cesium fluoride were used, with all the other conditions remained the same. However, this time a lot of diene 21 remained unreacted after 18 hours. After careful consideration of the potential source of the problem, we thought that this problem 
could come from the low solubility of diene 21 . Since 21 was not very soluble, once the very reactive benzyne 38a was generated in situ, there would not have enough diene $\mathbf{2 1}$ to react with it, and the highly reactive benzyne 38 a could then lead to some other reactions such as polymerization, which led to a lot of byproducts. In order to solve this problem, two modifications were made. The first one was using a mixed solvent of dichloromethane and acetonitrile to increase the solubility of diene, and the second one was adding the triflate dropwise over a period of 12 hours, which was achieved by utilizing a pressure equalizing funnel. In this way, the small amount of triflate which was dripped into the reaction mixture would react with the small amount of cesium fluoride that dissolved in acetonitrile to generate a small amount of benzyne, which would then immediately react with the diene that dissolved in the mixed solvent to form the desired DA adduct. And the experiment result proved that our hypothesis was correct, with much less byproducts formed. Also, by monitoring the reaction, it was found that all the diene was consumed after the addition of 2 equivalents of triflate. Unfortunately, when the same method was applied to 3-methoxybenzyne 38b and 3,6-dimethoxybenzyne 38c, which were generated from 3-methoxy-2-(trimethylsilyl)phenyl triflate (37b) and 3,6dimethoxy-2-(trimethylsilyl)phenyl triflate (37c), respectively, the yields were extremely low with most of the diene remained unreacted. Even by increasing the amount of triflates $\mathbf{3 8 b}$ and $\mathbf{3 8 c}$, the yields did not improve too much. 


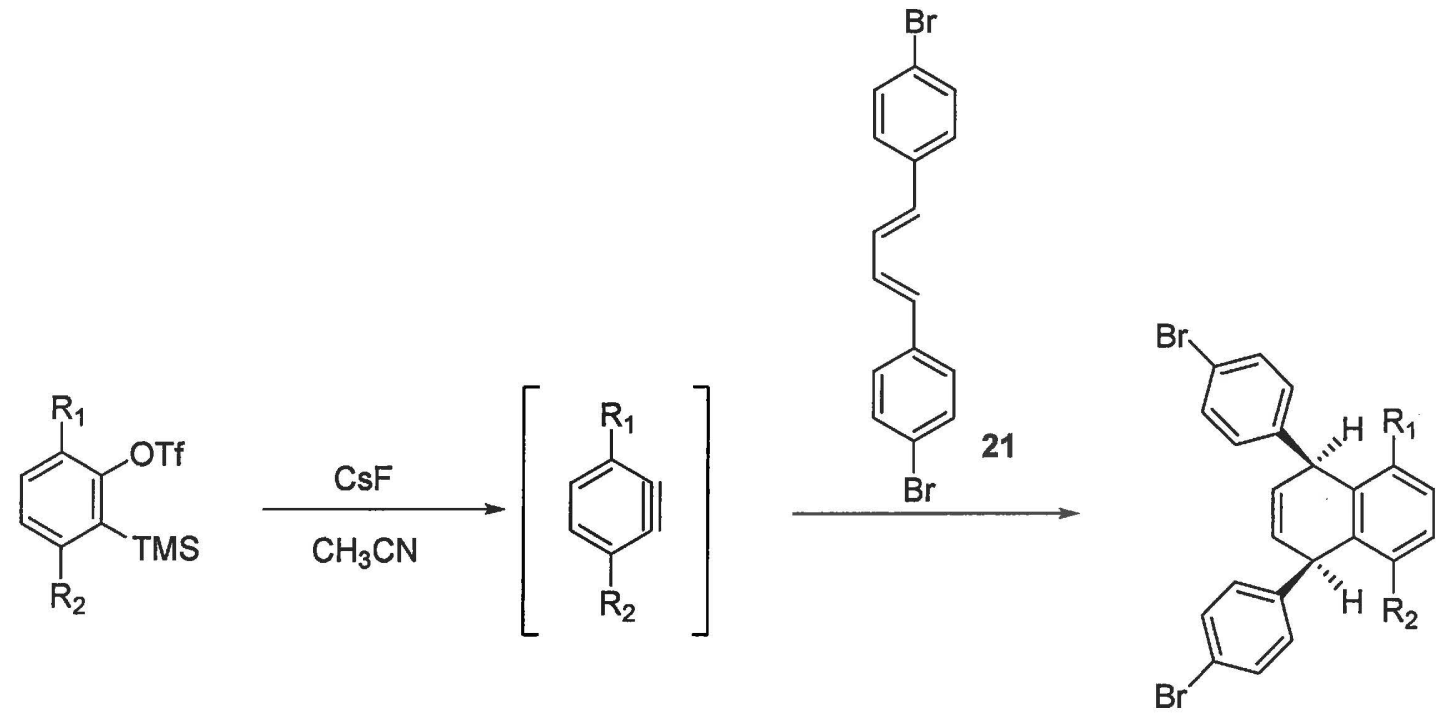
37a, $\mathrm{R}_{1}=\mathrm{R}_{2}=\mathrm{H}$
37b, $\mathrm{R}_{1}=\mathrm{H} \mathrm{R}_{2}=\mathrm{OMe}$
$37 \mathrm{c}, \mathrm{R}_{1}=\mathrm{R}_{2}=\mathrm{OMe}$
38a, $R_{1}=R_{2}=H$
$38 \mathrm{~b}, \mathrm{R}_{1}=\mathrm{H} \mathrm{R}_{2}=\mathrm{OMe}$
$38 \mathrm{c}, \mathrm{R}_{1}=\mathrm{R}_{2}=\mathrm{OMe}$

$18 \mathrm{a}, \mathrm{R}_{1}=\mathrm{R}_{2}=\mathrm{H}$

39, $\mathrm{R}_{1}=\mathrm{H} \mathrm{R}_{2}=\mathrm{OMe}$

$18 \mathrm{~b}, \mathrm{R}_{1}=\mathrm{R}_{2}=\mathrm{OMe}$

Scheme 9. Formation of benzynes for the Diels-Alder reactions with diene 21

Then the Diels-Alder reaction between diene 21 and $p$-benzoquinone was reinvestigated in the presence of a Lewis acid. Boron trifluoride-diethyl etherate, aluminum chloride and titanium tetrachloride were used to investigate the Lewis-acid catalyzed Diels-Alder reaction. ${ }^{31,32}$ The experiment was not successful in the case of $\mathrm{TiCl}_{4}$ catalyzed DA reaction, but the $\mathrm{BF}_{3} \cdot \mathrm{OEt}_{2}$-catalyzed $\mathrm{DA}$ reaction was very successful, and three products 40,41 and 42 were obtained after purification by flash column chromatography (Scheme 10). The X-ray crystal structures of $\mathbf{4 0}$ and $\mathbf{4 1}$ are shown in Figure 4. In a $1 \mathrm{~g}$-scale diene Diels-Alder reaction that was catalyzed by $\mathrm{BF}_{3} \cdot \mathrm{OEt}_{2}, 110$ $\mathrm{mg}$ of the benzoquinone adduct 40 (9\% yield), $62 \mathrm{mg}$ of the desired DA adduct 41 (5\% yield) and $940 \mathrm{mg}$ of a mixture of $\mathbf{4 1}$ and the hydroquinone adduct $\mathbf{4 2}$ were isolated (73\% yield total). The combined yield of $\mathbf{4 1}$ and $\mathbf{4 2}$ was $78 \%$. We expected adduct 41 could be converted to $\mathbf{4 2}$ upon purification by silica gel column chromatography. However since it 
was a relatively large scale reaction, the conversion from 41 to 42 was not complete. In order to convert $\mathbf{4 1}$ to $\mathbf{4 2}$, the mixture of $\mathbf{4 1}$ and $\mathbf{4 2}$ was treated with a $2 \mathrm{M}$ hydrochloric acid in methanol at $60^{\circ} \mathrm{C}$ for 1 hour. After purification by column chromatography, 720 $\mathrm{mg}$ of hydroquinone adduct $\mathbf{4 2}$ was obtained in $56 \%$ yield (calculation was based on $1 \mathrm{~g}$ of diene 21). Interestingly, bis-DA adduct 43 was obtained from the $\mathrm{AlCl}_{3}$-catalyzed $\mathrm{DA}$ reaction. The structure of $\mathbf{4 3}$ was established by X-ray structure analysis (Figure 5), and the X-ray crystal structure revealed that the four 4-bromophenyl groups are all cis to each other. This molecule is very interesting since it could allow us to synthesize a molecule bearing two cycloparaphenylene rings.

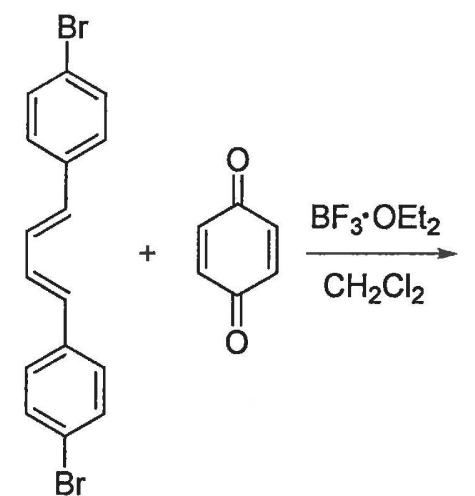

21<smiles>O=C1C=CC(=O)[C@@]2(O)C=C[C@](O)(c3ccc(Br)cc3)C(c3ccc(Br)cc3)C=C12</smiles>

40<smiles>O=C1C=CC(=O)[C@@H]2[C@@H]1C[C@H](c1ccc(Br)cc1)C=C[C@H]2c1ccc(Br)cc1</smiles>

41<smiles>[2H][C@]1(c2ccc(Br)cc2)C=C[C@@]([C])(c2ccc(Br)cc2)c2c(O)ccc(O)c21</smiles>

42

Scheme $10 . \mathrm{BF}_{3} \cdot \mathrm{OEt}_{2}$ catalyzed Diels-Alder reaction. 

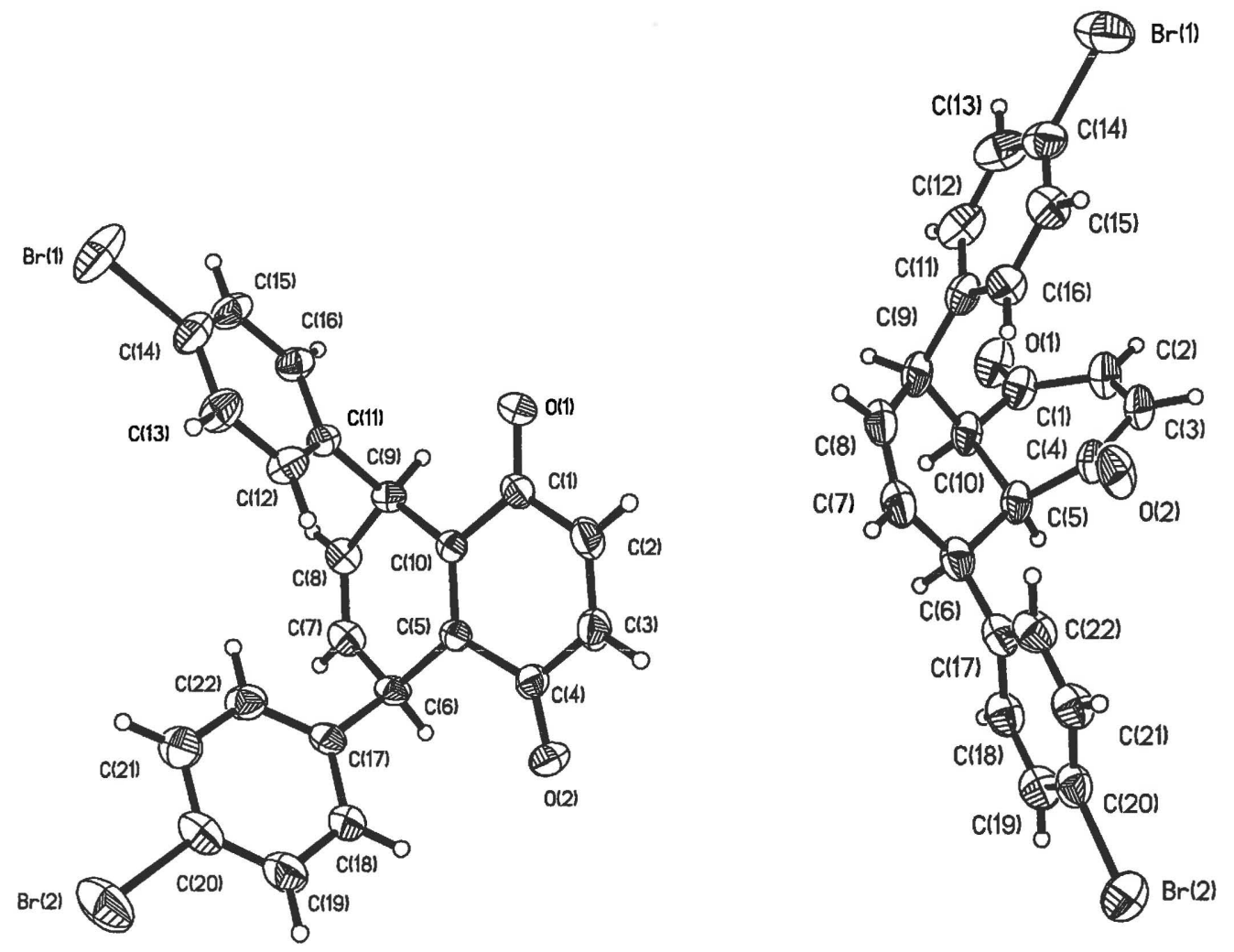

Figure 4. (Left) Perspective view of the molecular structure of $\mathrm{C}_{22} \mathrm{H}_{14} \mathrm{Br}_{2} \mathrm{O}_{2}(40)$ with the atom labeling scheme provided for the non-hydrogen atoms. The thermal ellipsoids are scaled to enclosed $30 \%$ probability. (Right) Perspective view of the molecular structure of $\mathrm{C}_{22} \mathrm{H}_{16} \mathrm{Br}_{2} \mathrm{O}_{2}$ (41) with the atom labeling scheme provided for the non-hydrogen atoms. The thermal ellipsoids are scaled to enclosed $30 \%$ probability. 
<smiles>O=C1C2=C(C(=O)[C@@H](c3ccc(Br)cc3)C3=C1[C@H](c1ccc(Br)cc1)C=C[C@H]3c1ccc(Br)cc1)[C@H](c1ccc(Br)cc1)C=C[C@H]2c1ccc(Br)cc1</smiles>

43

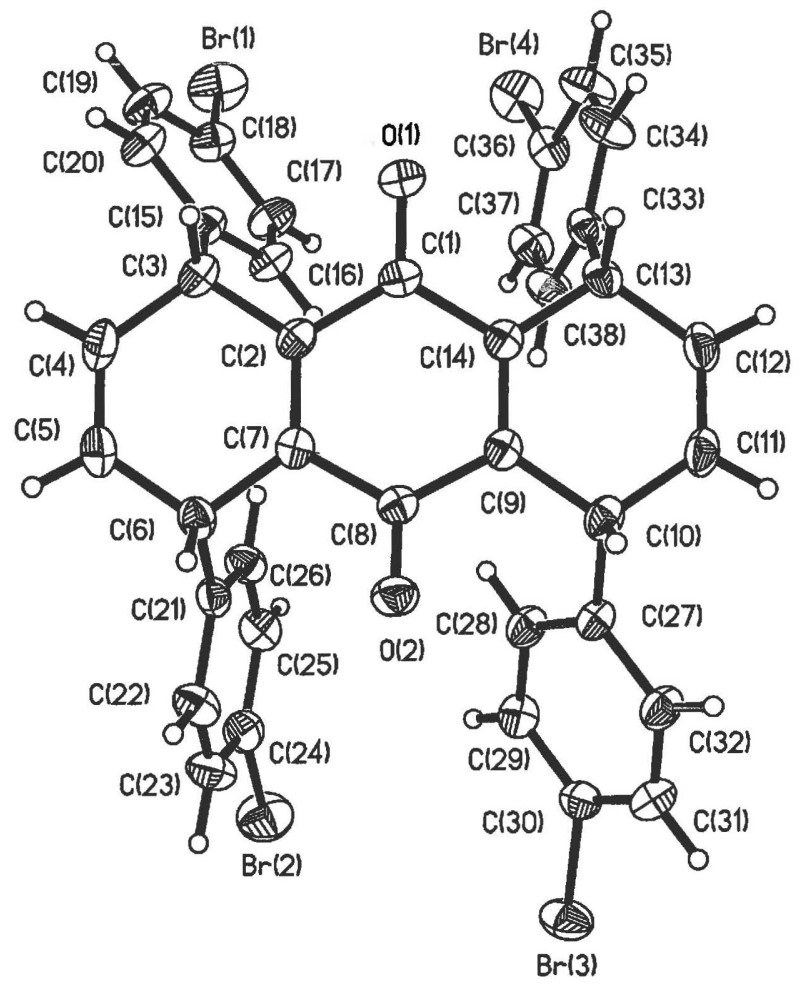

Figure 5. (Left) Structure of a bis-Diels-Alder adduct 43. (Right) Perspective view of the molecular structure of $\mathrm{C}_{38} \mathrm{H}_{24} \mathrm{Br}_{4} \mathrm{O}_{2}$ (43) with the atom labeling scheme provided for the non-hydrogen atoms. The thermal ellipsoids are scaled to enclosed $30 \%$ probability.

The methylation reaction of hydroquinone 42 was then carried out by treating 42 with a strong methylating reagent, dimethyl sulfate, in the presence of potassium carbonate in anhydrous acetone under reflux for 18 hours to afford dibromide $18 \mathrm{~b}$ in $79 \%$ yield (Scheme 11). ${ }^{33,34}$ After a literature review ${ }^{33}$, it is apparent that instead of converting 41 to 42 first, compound 41 could be used directly to conduct the methylation reaction using the same condition, so the conversion from $\mathbf{4 1}$ to $\mathbf{4 2}$ which was mentioned early 
was probably not necessary. It could save a step of the synthetic sequence with one less silica gel column chromatography, which could further improve the overall yield of the synthetic scheme. The structure of $\mathbf{1 8 b}$ was established by X-ray structure analysis (Figure 6). In the crystal structure of dibromide $\mathbf{1 8 b}$, the two 4-bromophenyl groups are not parallel to each other, which is different from our previous MM2-optimized structures. It is possible that the preferred conformation of the dibromide $\mathbf{1 8 b}$ in solution may be different from the one in crystal lattice.<smiles>Oc1ccc(O)c2c1[C@H](c1ccc(Br)cc1)C=C[C@H]2c1ccc(Br)cc1</smiles>

42

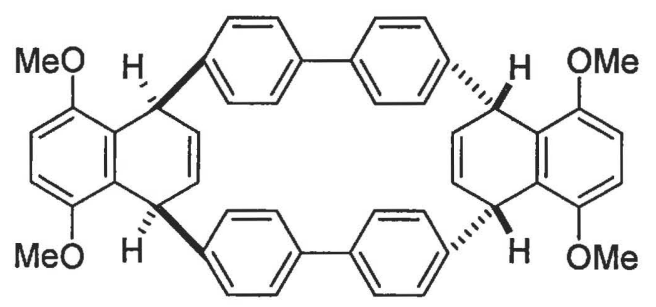<smiles>COc1ccc(OC)c2c1[C@H](c1ccc(Br)cc1)C=C[C@H]2c1ccc(Br)cc1</smiles>

$18 b$

$19 b$

Scheme 11. Synthesis of dibromide 18b and the [6]CPP derivative precursor 19b from hydroquinone 42. 


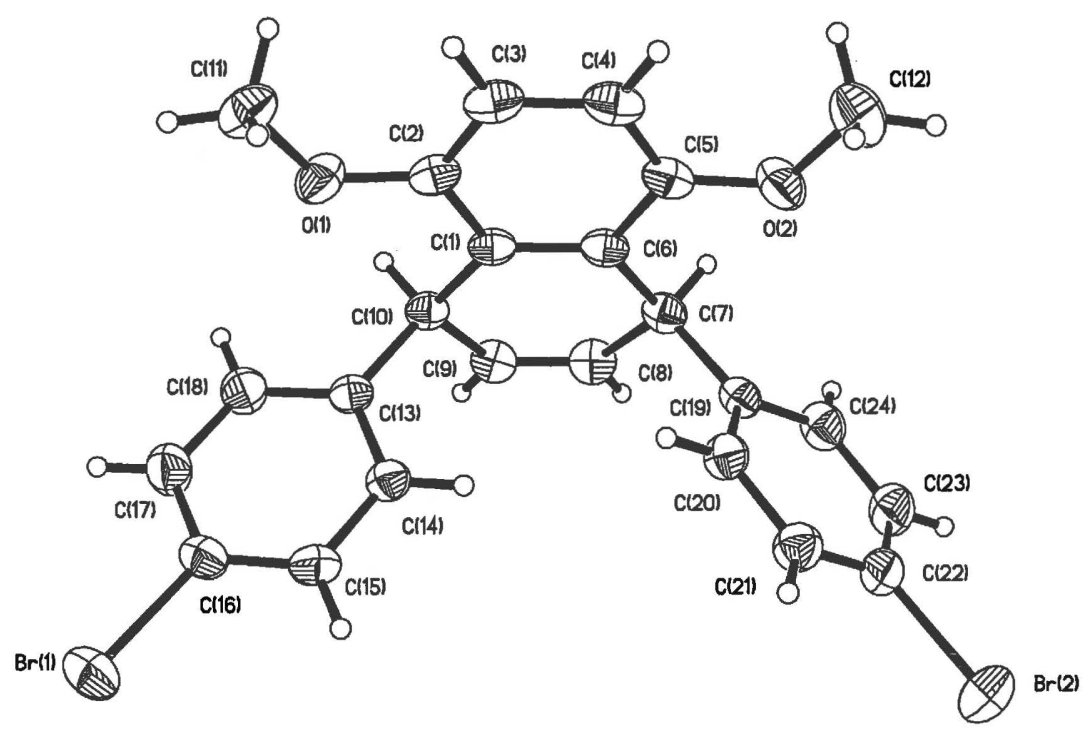

Figure 6. Perspective view of the molecular structure of $\mathrm{C}_{24} \mathrm{H}_{20} \mathrm{Br}_{2} \mathrm{O}_{2}$ (18b) with the atom labeling scheme provided for the non-hydrogen atoms. The thermal ellipsoids are scaled to enclosed $30 \%$ probability.

The [6]CPP derivative precursor $19 \mathrm{~b}$ was obtained by the nickel(0)-catalyzed homocoupling reaction (Scheme 11). Dibromide 18b, 2.5 equivalents of bis(1,5cyclooctadiene)nickel $(0)$ and 2.5 equivalents of $2,2^{\prime}$-bipyridyl were loaded in a glove box. Since the second step of the coupling reactions to form the dimer was an intramolecular reaction, a low concentration of monomer would increase the yield for the dimer. DMF was added to make the concentration of dibromide $18 \mathrm{~b}$ at $5.56 \mathrm{mM}$. The crude ${ }^{1} \mathrm{H}$ NMR spectrum indicated the existence of a ratio of 3:2 of the two diastereomers of the dimer 19b (Scheme 11), one with the methoxy signal at $3.84 \mathrm{ppm}$ (major), and the other at 3.86 ppm (minor). However, upon purification by flash column chromatography, only the 
major diastereomer of the dimer was successfully isolated in $21 \%$ yield. The ${ }^{1} \mathrm{H}$ and ${ }^{13} \mathrm{C}$ NMR spectra are consistent with the structure of $\mathbf{1 9 b}$. It is interesting to note that the signals from the aromatic hydrogens of the two biphenyl groups are shifted upfield significantly to $\delta 6.67$ (doublet) and $\delta 6.60$ (doublet). The upfield shifts of those proton signals can be attributed to the close proximity of the two biphenyl units, placing their aromatic hydrogens in the shielding regions of the aromatic ring current. In addition, the HRMS data further confirmed the formation of the dimer 19b. Furthermore, we believe that the more upfield methoxy signals (3.5-3.7 ppm) and more downfield aromatic proton signals (7.2-7.6 ppm) of the crude ${ }^{1} \mathrm{H}$ NMR spectrum were from trimers, tetramers, and perhaps cyclic products of larger ring sizes.

\section{Conclusion}

A synthetic pathway has been successful developed for the concise synthesis of 19b, which could serve as the precursor of the [6]cycloparaphenylene derivative 20b. The Lewis acid-catalyzed Diels-Alder reaction and the $\mathrm{Ni}(0)$-catalyzed homocoupling reaction are the two key steps of the synthetic sequence. It is envisioned that upon aromatization, compound $19 \mathrm{~b}$ could be converted to the [6]cycloparaphenylene derivative 20b as a carbon nanohoop of an armchair $(6,6)$ carbon nanotube. 


\section{Part II}

\section{Experimental Section}

Glassware used for all reactions were dried in an oven $\left(100^{\circ} \mathrm{C}\right)$ for at least 12 hours. All reactions were conducted under a nitrogen atmosphere unless otherwise indicated. Tetrahydrofuran ( $\geq 99.9 \%$, anhydrous, inhibitor-free), borane dimethyl sulfide complex, zinc chloride solution (0.5 M in THF), copper(I) iodide (98\%), catecholborane (98\%), benzene (99.8\%, anhydrous), thionyl chloride $(99.5 \%$, low iron), sulfur trioxide pyridine complex (98\%), diethyl ether ( $\geq 99.7 \%$, anhydrous, contains 1 ppm BHT as inhibitor), boron trifluoride diethyl etherate, 2-(trimethylsilyl)phenyl trifluoromethanesulfonate (97\%) (37a), dimethyl sulfate $(\geq 99.8 \%), 2,2^{\prime}$-bipyridyl $(\geq$ 99\%) were purchased from Aldrich. Cyclohexene (99\%), phenylacetylene (98\%), sodium methoxide (anhydrous powder), triethylamine (99.7\%), iodine (99.5\%, resublimed), sodium ethoxide ( $21 \%$ in ethanol), methanol (99.8\%, extra dry), diisobutylaluminium hydride (1M solution in hexane), toluene (99.8\%, extra dry), dichloromethane (99.9\%, extra dry, stabilized), dimethyl sulfoxide (99.7\%, extra dry, over molecular sieve), triethyl phosphite (98\%), potassium tert-butoxide (98+\%), p-benzoquinone (99\%), pxylene $(99 \%)$, hydroquinone $(99.5 \%)$, cesium fluoride $(99 \%)$, acetonitrile $(99.9 \%$, extra dry), aluminium chloride (98.5\%, anhydrous, powder), titanium(IV) chloride (1 M solution in dichloromethane), acetone (99.8\%, extra dry), $N, N$-dimethylformamide (99.8\%, extra dry) were purchased from Acros. Copper(I) bromide-dimethyl sulfide

complex was purchased from Alfa Aesar. 1-bromo-4-iodobenzene (99\%), (trimethylsilyl)acetylene (99\%), 4-bromocinnamic acid (98\%), 4-bromobenzyl bromide (99\%) were purchased from Oakwood. Trans- 
dichlorobis(triphenylphosphine)palladium(II) (99\%), tetrakis(triphenylphosphine) palladium(0) (99\%), bis(1,5-cyclooctadiene)nickel(0) (98+\%) were purchased from Strem. 3-Methoxy-2-(trimethylsilyl)phenyl trifluoromethanesulfonate ( $>95.0 \%)$ (37b) was purchased from TCI. Absolute ethanol was purchased from AAPER Alcohol and Chemical CO. Sodium hydroxide ( $\geq 97.0 \%$, pellets), potassium carbonate (anhydrous, $\geq 99.0 \%$, granular powder), glacial acetic acid ( $\geq 99.7 \mathrm{w} / \mathrm{w} \%$ ) were purchased from Fisher Chemical. All chemicals were used as received. Silica gel for flash column chromatography was purchased from Dynamic Adsorbents Inc. ${ }^{1} \mathrm{H}$ NMR $(600 \mathrm{MHz}),{ }^{13} \mathrm{C}$ NMR (150 MHz) and ${ }^{1} \mathrm{H}$ NMR (400 MHz), ${ }^{13} \mathrm{C}$ NMR (100 MHz) spectra were recorded in $\mathrm{CDCl}_{3}$ using $\mathrm{CHCl}_{3}\left({ }^{1} \mathrm{H} \delta\right.$ 7.26) and $\mathrm{CDCl}_{3}\left({ }^{13} \mathrm{C} \delta 77.0\right)$ as internal standards.

Compounds 21, 23, 24, 25, and 27 were prepared according to the reported procedure. ${ }^{19} 3,6$-Dimethoxy-2-(trimethylsilyl)phenyl trifluoromethanesulfonate (37c) was prepared according to the reported procedure. ${ }^{35,36}$

Compound 18a. To a mixture of $100 \mathrm{mg}$ of diene $21(0.275 \mathrm{mmol})$ and $125 \mathrm{mg}$ of cesium fluoride $(99 \%, 0.815 \mathrm{mmol})$ in $20 \mathrm{~mL}$ of anhydrous acetonitrile and $10 \mathrm{~mL}$ of anhydrous dichloromethane was added dropwise a solution of 2-(trimethylsilyl)phenyl triflate $(97 \%, 0.553 \mathrm{mmol})$ in $25 \mathrm{~mL}$ of anhydrous acetonitrile from a pressure equalizing funnel under a nitrogen atmosphere. The addition was finished in 12 hours. After an additional 6 hours of stirring, distilled water was added and the reaction mixture was extracted with dichloromethane. The combined organic layers were dried over sodium sulfate and concentrated. The residue was purified by flash column chromatography 
(silica gel, ethyl acetate:hexanes $=1: 10)$ to produce $98 \mathrm{mg}$ of $18 \mathbf{a}(0.223 \mathrm{mmol}, 81 \%$ yield) as a yellow solid (initially a viscous oil which under vacuum became a foam-like solid): ${ }^{1} \mathrm{H}$ NMR $\left(\mathrm{CDCl}_{3}, 400 \mathrm{MHz}\right) \delta 7.45(4 \mathrm{H}, \mathrm{d}, J=8.4 \mathrm{~Hz}), 7.09-7.12(6 \mathrm{H}, \mathrm{m}), 6.99-$ $7.01(2 \mathrm{H}, \mathrm{m}), 5.91(2 \mathrm{H}, \mathrm{d}, J=1.6 \mathrm{~Hz}), 4.69(2 \mathrm{H}, \mathrm{d}, J=1.2 \mathrm{~Hz}) ;{ }^{13} \mathrm{C} \mathrm{NMR}\left(\mathrm{CDCl}_{3}, 100\right.$ MHz) $\delta 144.47,136.06,131.75,130.38,129.55,127.86,126.69,120.42,44.80$. HRMS calcd for $\mathrm{C}_{22} \mathrm{H}_{16} \mathrm{Br}_{2} \mathrm{Na}\left(\mathrm{MNa}^{+}\right)$462.9491, found 462.9485 .

Compound 43. A mixture of $36 \mathrm{mg}$ of 1,4-benzoquinone $(0.330 \mathrm{mmol})$ and $66 \mathrm{mg}$ of aluminium chloride $(0.488 \mathrm{mmol})$ in $30 \mathrm{~mL}$ of anhydrous dichloromethane was stirred under a nitrogen atmosphere at room temperature for 5 minutes. Then a solution of 100 $\mathrm{mg}$ of diene $21(0.275 \mathrm{mmol})$ in $40 \mathrm{~mL}$ of anhydrous dichloromethane was added via cannula. The reaction mixture was stirred at room temperature for 45 hours. Distilled water was slowly added, and the reaction mixture was extracted with ethyl acetate. The combined organic layers were dried over sodium sulfate and concentrated. The residue was purified by flash column chromatography (silica gel, ethyl acetate:hexanes $=1: 10$ and then 1:5) to produce $18 \mathrm{mg}$ of $43(0.022 \mathrm{mmol}, 16 \%$ yield $)$ as a yellow solid: ${ }^{1} \mathrm{H}$ NMR $\left(\mathrm{CDCl}_{3}, 400 \mathrm{MHz}\right) \delta 7.26(8 \mathrm{H}, \mathrm{d}, J=8.8 \mathrm{~Hz}), 6.80(8 \mathrm{H}, \mathrm{d}, J=8.8 \mathrm{~Hz}), 5.84(4 \mathrm{H}$, d, $J=2.8 \mathrm{~Hz}), 4.67(4 \mathrm{H}, \mathrm{d}, J=2.4 \mathrm{~Hz}) ;{ }^{13} \mathrm{C} \mathrm{NMR}\left(\mathrm{CDCl}_{3}, 100 \mathrm{MHz}\right) \delta 185.43,141.31$, $139.82,131.77,129.61,126.28,120.90,39.29$. Recrystallization of 43 from dichloromethane/hexanes produced a single crystal suitable for X-ray structure analysis. 
Compounds 40, 41, and 42. To a mixture of $1.00 \mathrm{~g}$ of diene $21(2.75 \mathrm{mmol})$ and $0.360 \mathrm{~g}$ of 1,4-benzoquinone $(3.30 \mathrm{mmol})$ in $200 \mathrm{~mL}$ of anhydrous dichloromethane under a nitrogen atmosphere was added by using a syringe $0.61 \mathrm{~mL}$ of boron trifluoride-diethyl etherate $(4.94 \mathrm{mmol})$. The reaction mixture was stirred at room temperature for 20 hours. Distilled water was slowly added and the reaction mixture was extracted with ethyl acetate. The combined organic layers were dried over sodium sulfate and concentrated. The residue was purified by flash column chromatography (silica gel, ethyl acetate:hexanes $=1: 10$ and then $1: 5)$ to produce $110 \mathrm{mg}$ of $\mathbf{4 0}(0.234 \mathrm{mmol}, 9 \%$ yield $)$ as a yellow solid, $62 \mathrm{mg}$ of $41(0.131 \mathrm{mmol}, 5 \%$ yield $)$ as a yellow solid and $940 \mathrm{mg}$ of a mixture of $\mathbf{4 1}$ and $\mathbf{4 2}$ as a yellow solid. To the $940 \mathrm{mg}$ mixture of $\mathbf{4 1}$ and $\mathbf{4 2}$ in methanol was added a $2 \mathrm{M}$ hydrochloric acid and the reaction mixture was heated at $60^{\circ} \mathrm{C}$ for 1 hour under a nitrogen atmosphere. Water was added and the reaction mixture was extracted with ethyl acetate. The combined organic layers were dried over sodium sulfate and concentrated. Purification by flash column chromatography (silica gel, ethyl acetate:hexanes $=1: 5)$ produced $720 \mathrm{mg}$ of $\mathbf{4 2}(1.52 \mathrm{mmol}, 56 \%$ yield $)$ as a white solid. Compound 40: ${ }^{1} \mathrm{H} \mathrm{NMR}\left(\mathrm{CDCl}_{3}, 600 \mathrm{MHz}\right) \delta 7.43(4 \mathrm{H}, \mathrm{d}, J=9.0 \mathrm{~Hz}), 7.15(4 \mathrm{H}, \mathrm{d}, J=$ $7.8 \mathrm{~Hz}), 6.69(2 \mathrm{H}, \mathrm{s}), 5.91(2 \mathrm{H}, \mathrm{d}, J=2.4 \mathrm{~Hz}), 4.72(2 \mathrm{H}, \mathrm{d}, J=3.0 \mathrm{~Hz}) ;{ }^{13} \mathrm{C}$ NMR $\left(\mathrm{CDCl}_{3}, 150 \mathrm{MHz}\right) \delta 185.97,141.55,140.17,136.41,131.78,130.14,126.51,120.96$, 39.95. Compound 41: ${ }^{1} \mathrm{H}$ NMR $\left(\mathrm{CDCl}_{3}, 600 \mathrm{MHz}\right) \delta 7.39(4 \mathrm{H}, \mathrm{d}, J=9.0 \mathrm{~Hz}), 7.08(4 \mathrm{H}$, d, $J=8.4 \mathrm{~Hz}), 6.20(2 \mathrm{H}, \mathrm{s}), 5.99(2 \mathrm{H}, \mathrm{s}), 3.84(2 \mathrm{H}, \mathrm{d}, J=6.6 \mathrm{~Hz}), 3.71(2 \mathrm{H}, \mathrm{d}, J=6.6$ $\mathrm{Hz}) ;{ }^{13} \mathrm{C} \mathrm{NMR}\left(\mathrm{CDCl}_{3}, 150 \mathrm{MHz}\right) \delta 198.69,139.98,138.49,131.18,131.11,128.63$, 121.03, 51.49, 41.14. Compound 42: ${ }^{1} \mathrm{H}$ NMR $\left(\mathrm{CDCl}_{3}, 600 \mathrm{MHz}\right) \delta 7.42(4 \mathrm{H}, \mathrm{d}, J=8.4$ $\mathrm{Hz}), 7.14(4 \mathrm{H}, \mathrm{d}, J=9.0 \mathrm{~Hz}), 6.63(2 \mathrm{H}, \mathrm{s}), 5.90(2 \mathrm{H}, \mathrm{d}, J=2.4 \mathrm{~Hz}), 4.78(2 \mathrm{H}, \mathrm{d}, J=$ 
3.0 Hz), $4.29(2 \mathrm{H}, \mathrm{br}) ;{ }^{13} \mathrm{C} \mathrm{NMR}\left(\mathrm{CDCl}_{3}, 150 \mathrm{MHz}\right) \delta 147.37,142.35,131.88,129.72$, $127.27,124.78,120.59,115.07,40.83$. Recrystallization of 40 and 41 from dichloromethane/hexanes produced single crystals suitable for X-ray structure analyses.

Compound 18b. To a mixture of $0.693 \mathrm{~g}$ of $42(1.48 \mathrm{mmol})$ and $2.840 \mathrm{~g}$ of potassium carbonate $(20.5 \mathrm{mmol})$ in $100 \mathrm{~mL}$ of anhydrous acetone under a nitrogen atmosphere was added $1.4 \mathrm{~mL}$ of dimethyl sulfate $(14.8 \mathrm{mmol})$ via a syringe, and the reaction mixture was then heated under reflux for 18 hours. Water was added and the reaction mixture was extracted with ethyl acetate and then dichloromethane. The combined organic layers were dried over sodium sulfate and concentrated. The crude solid residue was purified by flash column chromatography (silica gel, ethyl acetate:hexanes $=1: 5$ ) to produce $0.580 \mathrm{~g}$ of 18b (1.16 mmol, 79\% yield) as a white solid: ${ }^{1} \mathrm{H} \mathrm{NMR}\left(\mathrm{CDCl}_{3}, 600 \mathrm{MHz}\right) \delta 7.33(4 \mathrm{H}, \mathrm{d}$, $J=8.4 \mathrm{~Hz}), 7.05(4 \mathrm{H}, \mathrm{d}, J=9.0 \mathrm{~Hz}), 6.73(2 \mathrm{H}, \mathrm{s}), 5.95(2 \mathrm{H}, \mathrm{d}, J=3.0 \mathrm{~Hz}), 4.83(2 \mathrm{H}, \mathrm{d}$, $J=3.0 \mathrm{~Hz}), 3.61(6 \mathrm{H}, \mathrm{s}) ;{ }^{13} \mathrm{C} \mathrm{NMR}\left(\mathrm{CDCl}_{3}, 150 \mathrm{MHz}\right) \delta 151.23,143.67,131.04,129.85$, $127.74,127.01,119.52,109.21,55.64,40.57$. HRMS calcd for $\mathrm{C}_{24} \mathrm{H}_{21} \mathrm{Br}_{2} \mathrm{O}_{2}\left(\mathrm{MH}^{+}\right)$ 498.9903, found 498.9910; calcd for $\mathrm{C}_{24} \mathrm{H}_{20} \mathrm{Br}_{2} \mathrm{O}_{2} \mathrm{Na}\left(\mathrm{MNa}^{+}\right)$520.9722, 522.9702, 524.9681 , found $520.9736,522.9708,524.9689$, respectively. Recrystallization of $\mathbf{1 8 b}$ from chloroform/hexanes produced a single crystal suitable for X-ray structure analysis.

Compound 19b. In a glove box, a 250-mL flask was charged with $0.500 \mathrm{~g}$ of $18 \mathrm{~b}(1.00$ mmol), $0.702 \mathrm{~g}$ of bis(cyclooctadiene)nickel(0) $(2.50 \mathrm{mmol})$ and $0.394 \mathrm{~g}$ of 2,2'bipyridyl $(2.50 \mathrm{mmol})$ and then fitted with a water condenser followed by the addition of 
$180 \mathrm{~mL}$ of $N, N$-dimethylformamide. The reaction mixture was heated at $85^{\circ} \mathrm{C}$ for 44 hours under a nitrogen atmosphere. After the mixture was allowed to cool to room temperature, brine was added, and the reaction mixture was extracted with ethyl acetate and dichloromethane. The combined organic layers were dried over sodium sulfate and concentrated. The residue was purified by flash column chromatography (silica gel, ethyl acetate:hexanes $=1: 20$ then $1: 10)$ to produce $72 \mathrm{mg}$ of $19 \mathrm{~b}(0.106 \mathrm{mmol}, 21 \%$ yield $)$ as a white solid: ${ }^{1} \mathrm{H}$ NMR $\left(\mathrm{CDCl}_{3}, 400 \mathrm{MHz}\right) \delta 6.90(4 \mathrm{H}, \mathrm{s}), 6.78-6.79(4 \mathrm{H}, \mathrm{m}), 6.67(8 \mathrm{H}, \mathrm{d}$, $J=8.4 \mathrm{~Hz}), 6.60(8 \mathrm{H}, \mathrm{d}, J=8.0 \mathrm{~Hz}), 5.17-5.18(4 \mathrm{H}, \mathrm{m}), 3.84(12 \mathrm{H}, \mathrm{s}) ;{ }^{13} \mathrm{C} \mathrm{NMR}$ $\left(\mathrm{CDCl}_{3}, 100 \mathrm{MHz}\right) \delta 150.93,140.24,138.35,133.24,131.41,127.35,125.90,108.51$, 55.91, 37.33. HRMS calcd for $\mathrm{C}_{48} \mathrm{H}_{40} \mathrm{O}_{4}\left(\mathrm{M}^{+}\right)$680.2921, found 680.2923; calcd for $\mathrm{C}_{48} \mathrm{H}_{41} \mathrm{O}_{4}\left(\mathrm{MH}^{+}\right)$681.2999, found 681.3009. 


\section{REFERENCES}

[1] Radushkevich, L. V.; Lukyanovich, V. M. Zh. Fiz. Khim. 1952, 26, 88-95.

[2] Prasek, J.; Drbohlavova, J.; Chomoucka, J.; Hubalek, J.; Jasek, O.; Adam, V.; Kizek, R. J. Mater. Chem. 2011, 21, 15872-15884.

[3] Jasti, R.; Bhattacharjee, J.; Neaton, J. B.; Bertozzi, C. R. J. Am. Chem. Soc. 2008, 130, $17646-17647$.

[4] Yamago, S.; Watanabe, Y.; Iwamoto, T. Angew. Chem. Int. Ed. 2010, 49, 757-759.

[5] Takaba, H.; Omachi, H.; Yamamoto, Y.; Bouffard, J.; Itami, K. Angew. Chem. Int. Ed. $2009,48,6112-6116$.

[6] Xia, J.; Jasti, R. Angew. Chem. Int. Ed. 2012, 51, 2474-2476.

[7] Sisto, T. J.; Golder, M. R.; Hirst, E. S.; Jasti, R. J. Am. Chem. Soc. 2011, 133, 1580015802.

[8] Darzi, E. R.; Sisto, T. J.; Jasti, R. J. Org. Chem. 2012, 77, 6624-6628.

[9] Iwamoto, T.; Watanabe, Y.; Sakamoto, Y.; Suzuki, T.; Yamogo, S. J. Am. Chem. Soc. 2011, 133, 8354-8361.

[10] Segawa, Y.; Šenel, P.; Matsuura, S.; Omachi, H.; Itami, K. Chem. Lett. 2011, 40, $423-425$.

[11] Kayahara, E.; Sakamoto, Y.; Suzuki, T.; Yamago, S. Org. Lett. 2012, 14, 3284-3287. 
[12] Segawa, Y.; Miyamoto, S.; Omachi, H.; Matsuura, S.; Šenel, P.; Sasamori, T.;

Tokitoh, N.; Itami, K. Angew. Chem. Int. Ed. 2011, 50, 3244-3248.

[13] Omachi, H.; Matsuura, S.; Segawa, Y.; Itami, K. Angew. Chem. Int. Ed. 2010, 49, $10202-10205$.

[14] Omachi, Haruka.; Segawa, Y.; Itami, K. Org. Lett. 2011, 13, 2480-2483.

[15] Yagi, A.; Segawa, Y.; Itami, K. J. Am. Chem. Soc. 2012, 134, 2962-2965.

[16] Xia, J.; Golder, M. R.; Foster, M. E.; Wong, B. M.; Jasti, R. J. Am. Chem. Soc. 2012, 134, 19709-19715.

[17] Sisto, T. J.; Tian, X.; Jasti, R. J. Org. Chem. 2012, 77, 5857-5860.

[18] Matsui, K.; Segawa, Y.; Itami, K. Org. Lett. 2012, 14, 1888-1891.

[19] Davis, M. C.; Groshens, T. J. Synth. Commun. 2011, 41, 206-218.

[20] Brown, H. C. Organic Syntheses via Boranes; Wiley-Interscience: New York, 1975.

[21] Zweifel, G.; Clark, G. M.; Polston, N. L. J. Am. Chem. Soc. 1971, 93, 3395-3399.

[22] Molander, G. A.; Zinke, P. W. Organometallics, 1986, 5, 2161-2162.

[23] Campbell, J. B.; Brown, H. C. J. Org. Chem. 1980, 45, 549-550.

[24] Brown, H. C.; Hamaoka, T.; Ravindran, N. J. Am. Chem. Soc. 1973, 95, 5786-5788.

[25] Miyaura, N.; Yamada, K.; Suginome, H.; Suzuki, A. J. Am. Chem. Soc. 1985, 107, 972-980. 
[26] Braude, E. A.; Jones, E. R. H.; Stern, E. S. J. Chem. Soc. 1947, 1087-1096.

[27] Ballistreri, F. P., Maccarone, E.; Perrini, G.; Tomaselli, G. A.; Torre, M. J. Chem. Soc., Perkin Trans. 2 1982, 3, 273-277.

[28] Frimer, A. A.; Gilinsky-Sharon, P.; Gottlieb, H. E.; Meador, M. A. B.; Johnston, J. C. Macromolecules 2005, 38, 1504-1507.

[29] Lepage, Y. Bulletin de la Société Chimique de France 1963, 10, 2019-2022.

[30] Braude, E. A.; Fawcett, J. S.; Webb, A. A. J. Chem. Soc. 1954, 1049-1059.

[31] Bhargava, G.; Mahajan, M. P.; Saito, T.; Otani, T.; Kurashima, M.; Sakai, K. Eur. J. Org. Chem. 2005, 2005, 2397-2405.

[32] Castro, M. A.; Miguel del Corral, J. M.; Gordaliza, M.; García, P. A.; Gamito, A. M.; Gualberto, S. A.; Batista, R.; San Feliciano, A. Synthesis 2005, 19, 3202-3208.

[33] Carreño, M. C.; García-Cerrada, S.; Urbano, A. Chem. Eur. J. 2003, 9, 4118-4131.

[34] Lou, K.; Prior, A. M.; Wiredu, B.; Desper, J.; Hua, D. H. J. Am. Chem. Soc. 2010, $132,17635-17641$.

[35] Yoshida, H.; Sugiura, S.; Kunai, A. Org. Lett. 2002, 4, 2767-2769.

[36] Peña, D.; Pérez, D.; Guitián, E.; Castedo, L. J. Am. Chem. Soc. 1999, 121, 58275828. 
APPENDIX 


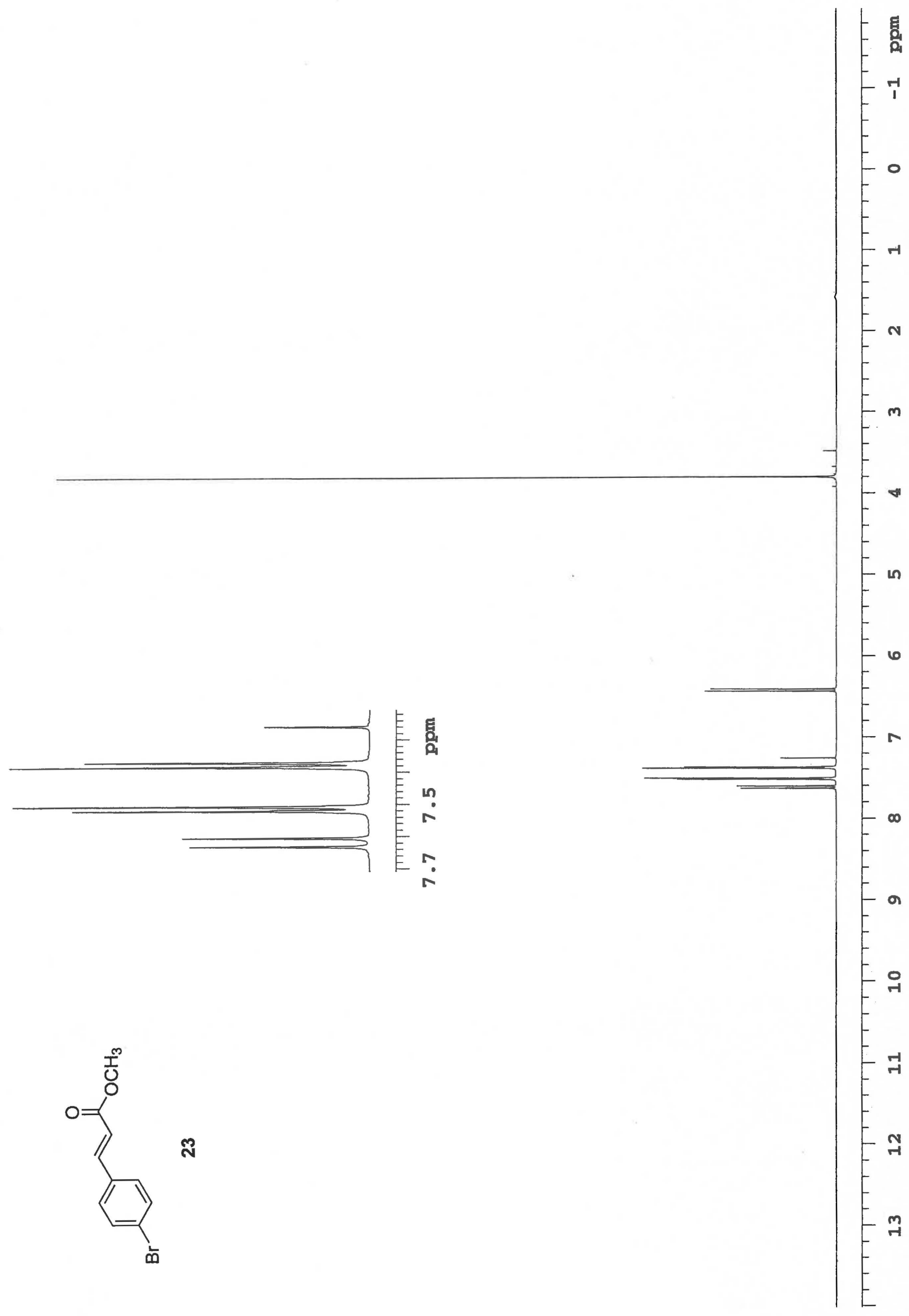




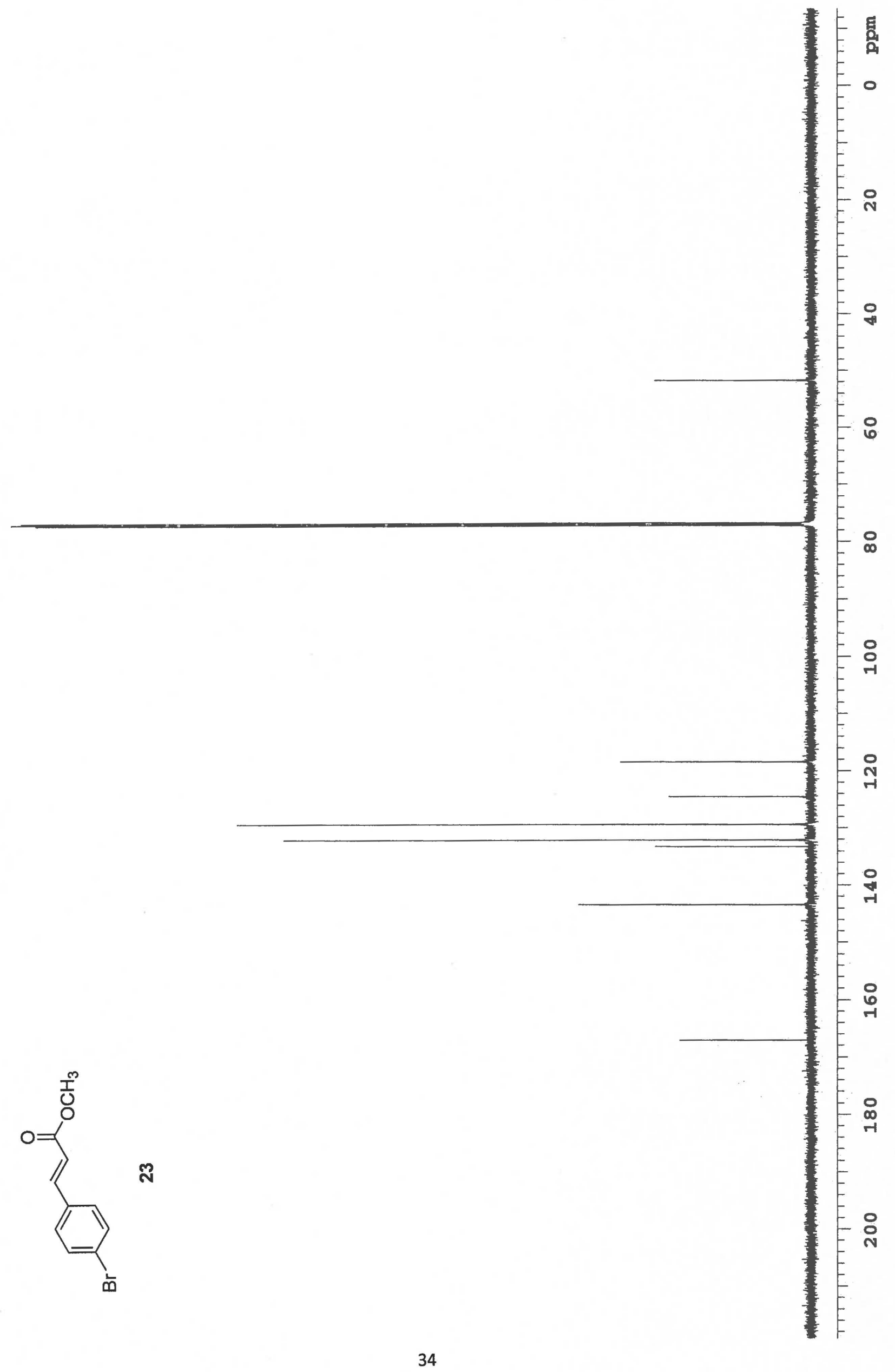



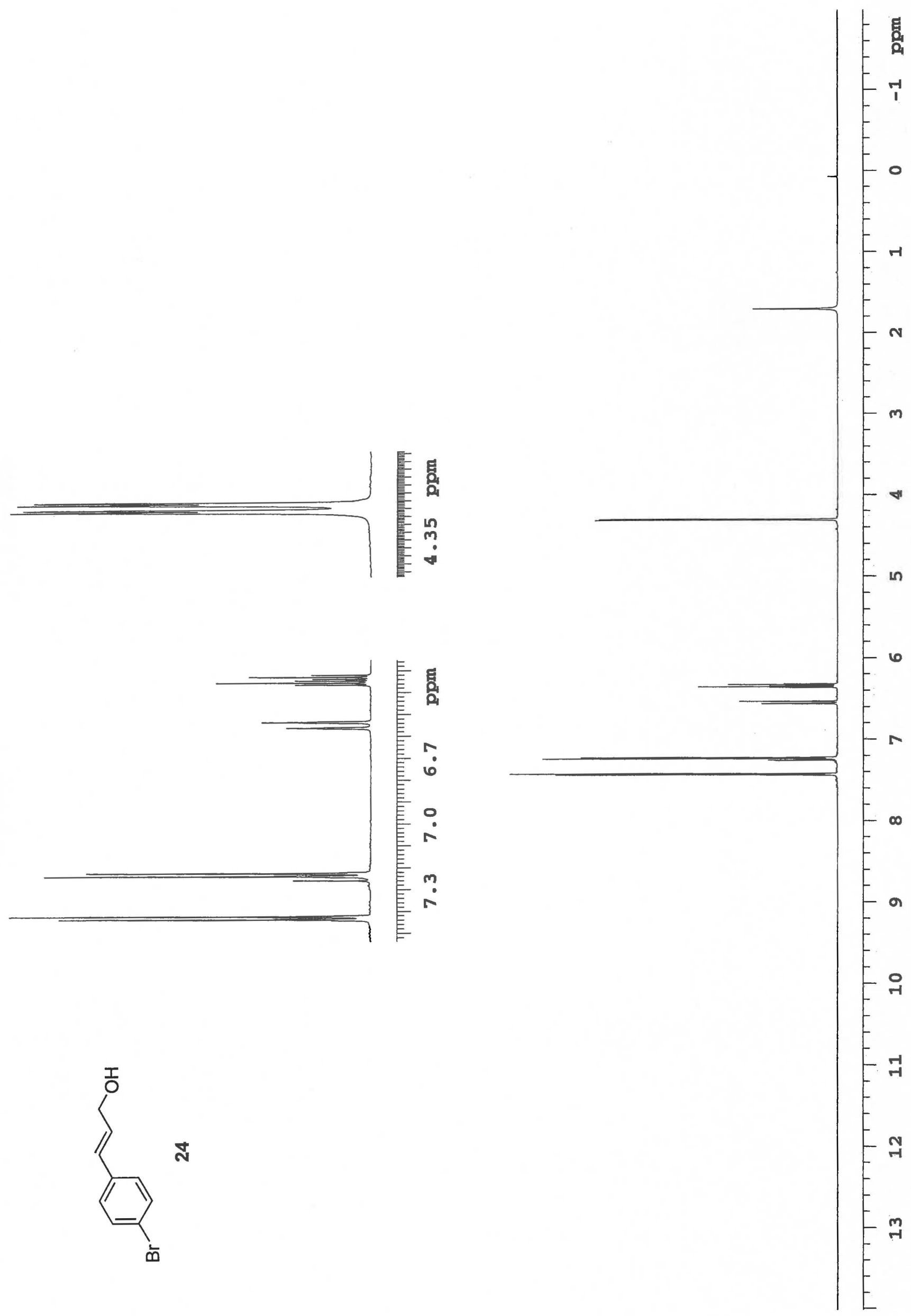


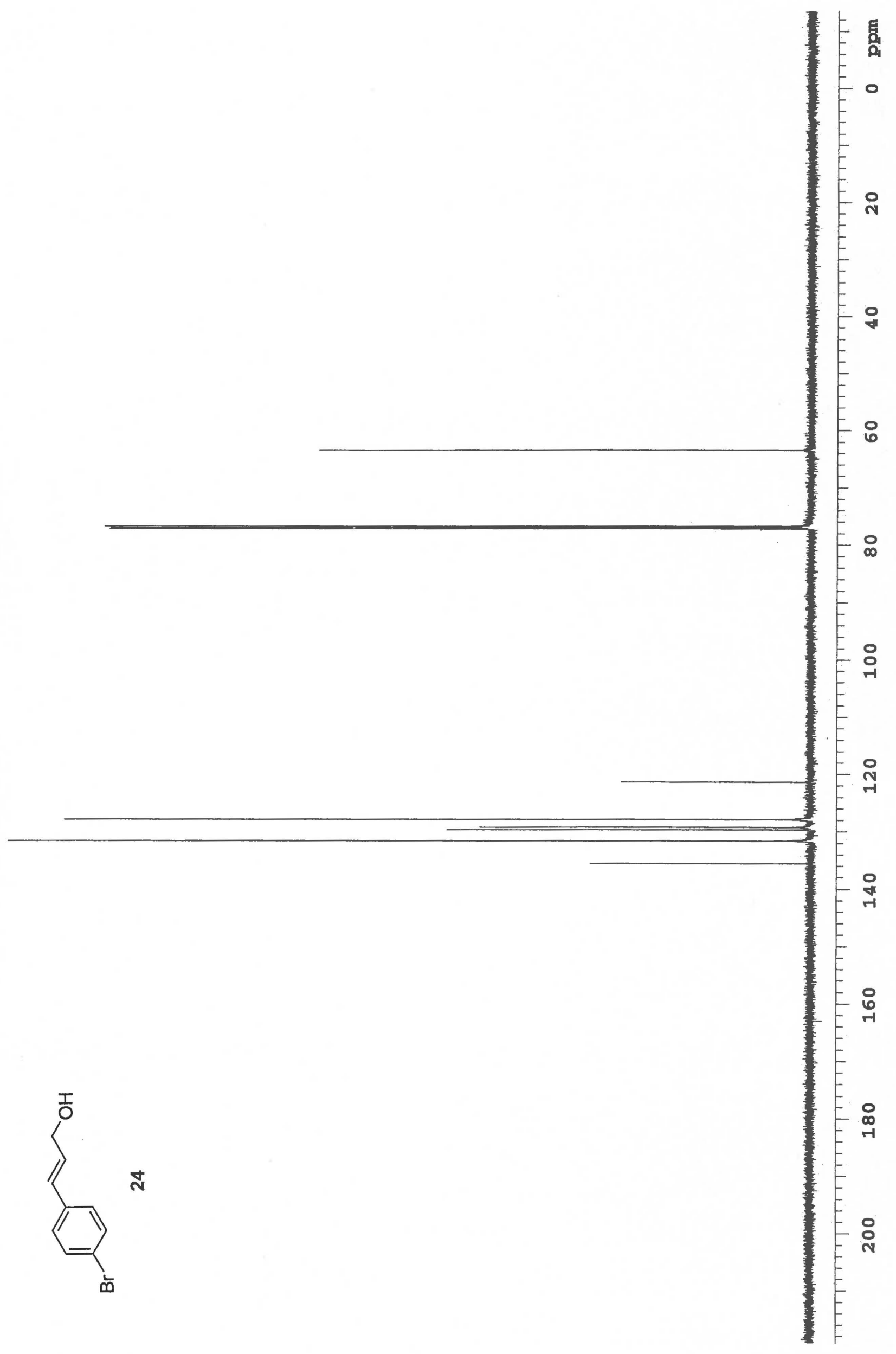




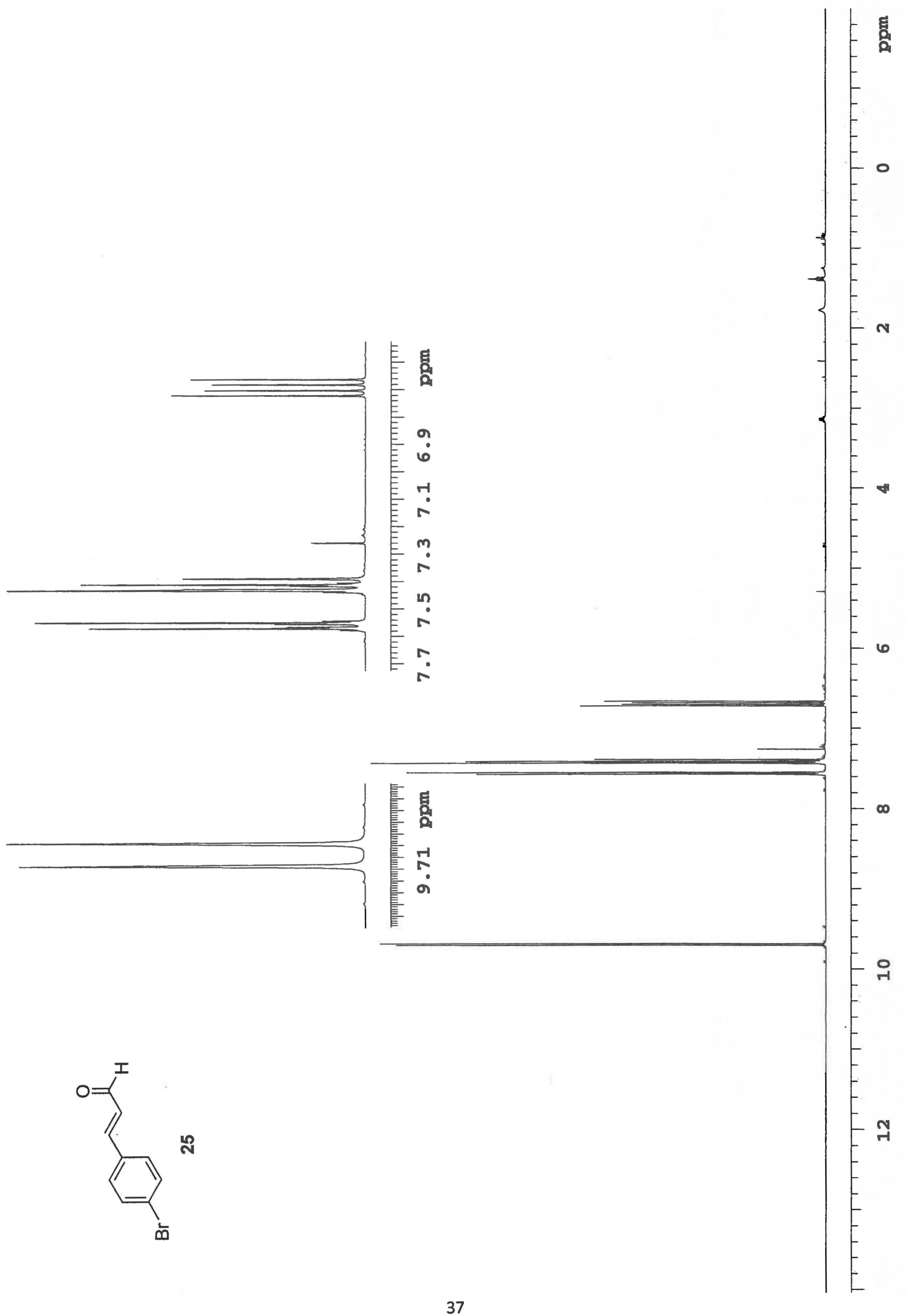




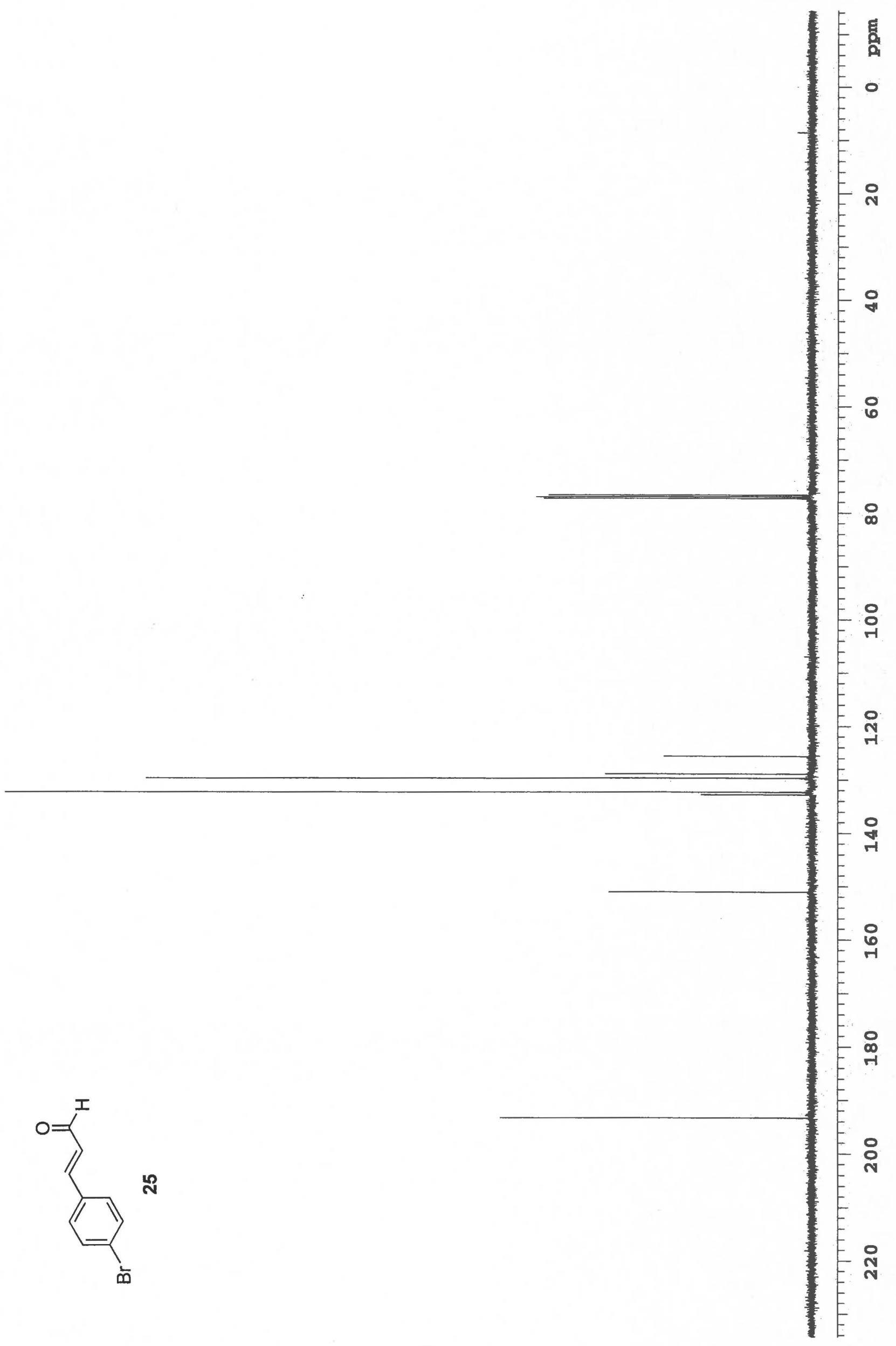




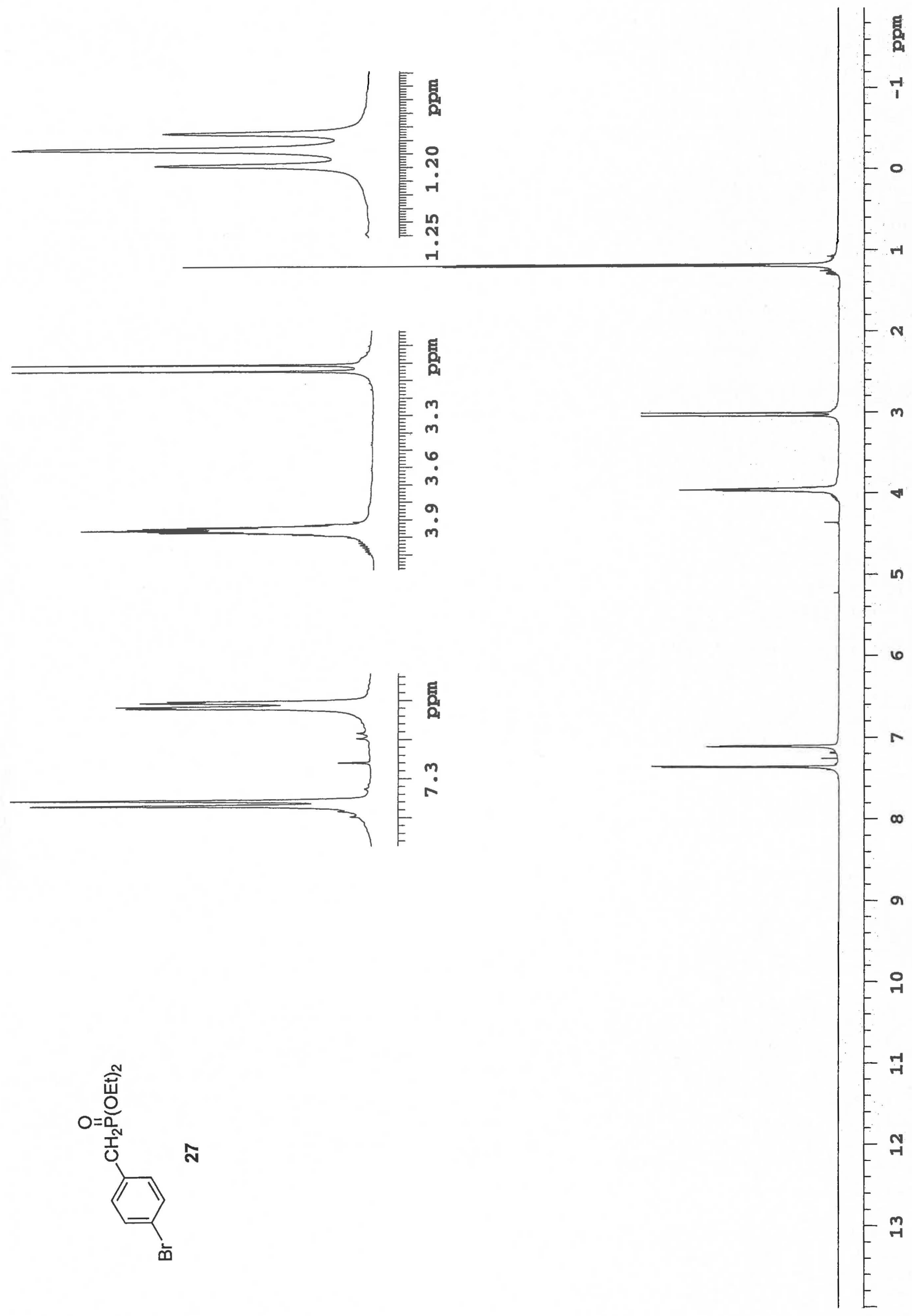




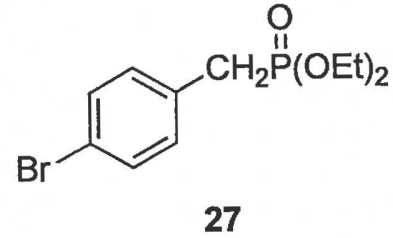

8

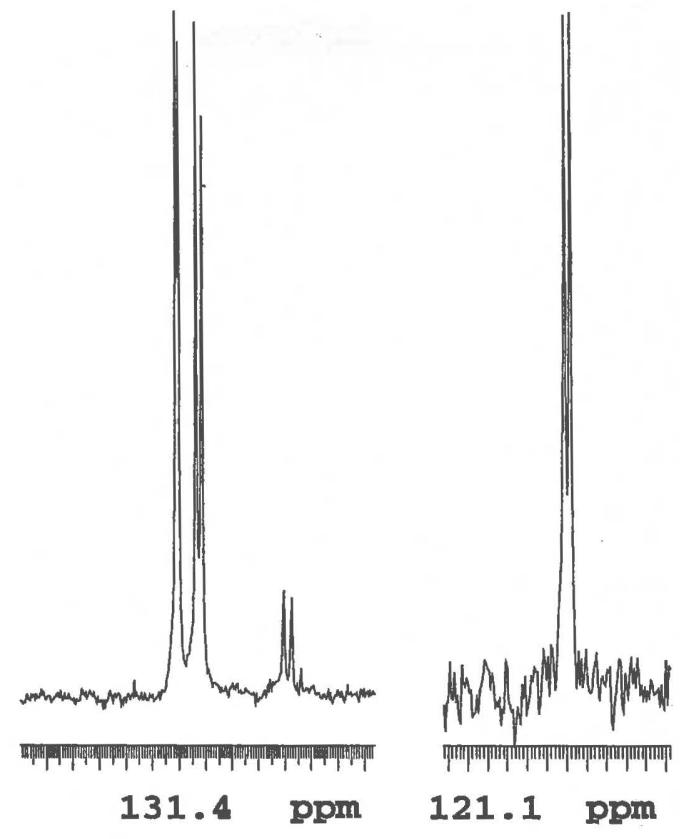

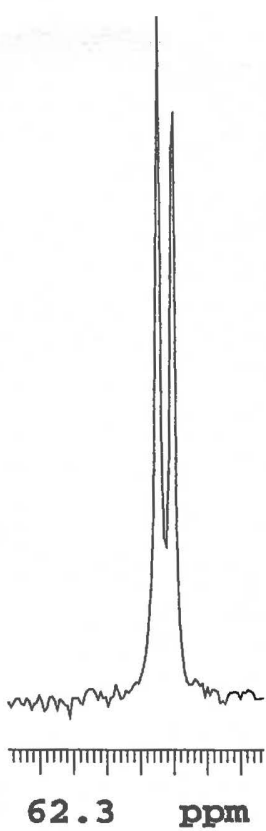
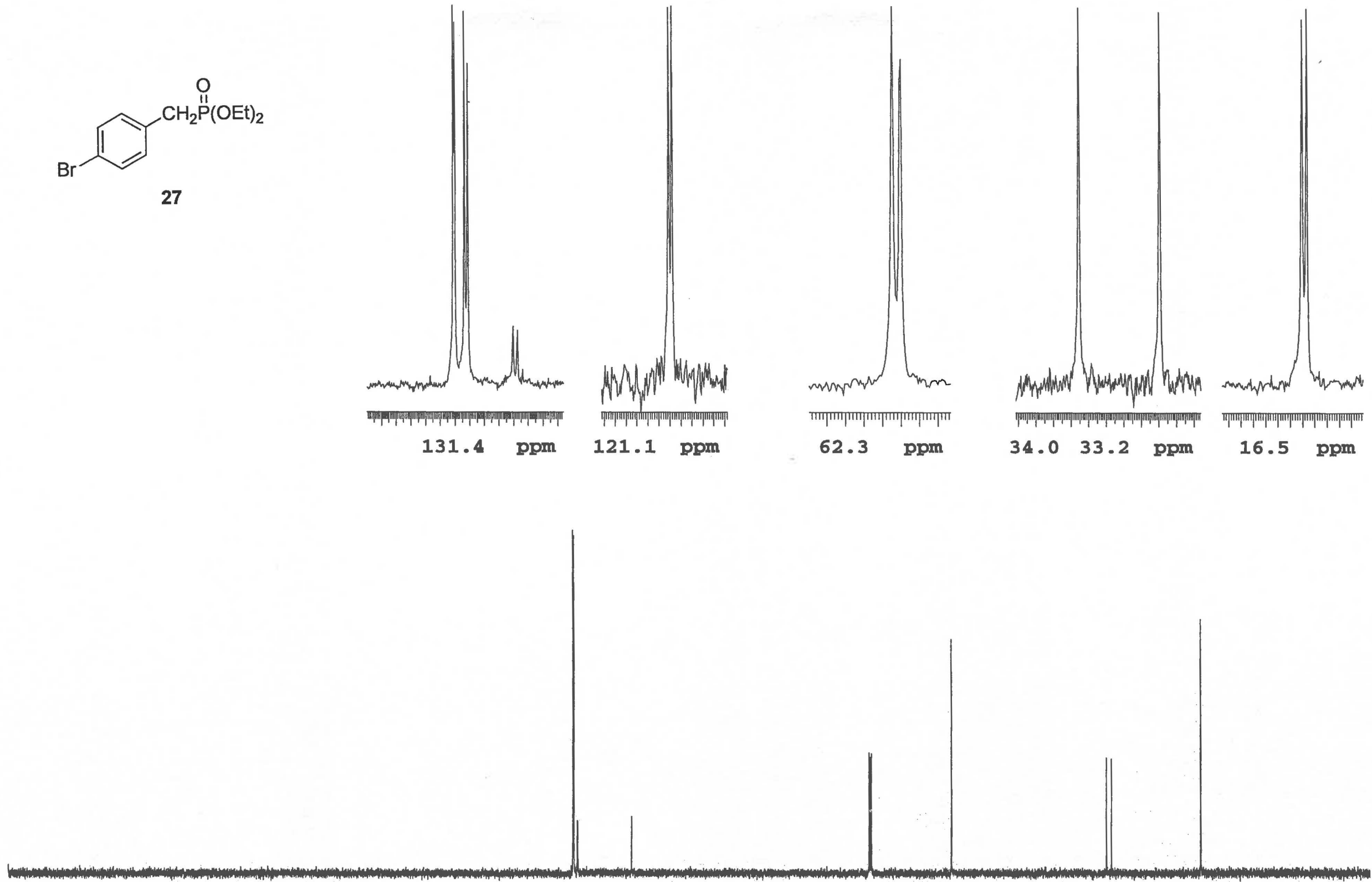

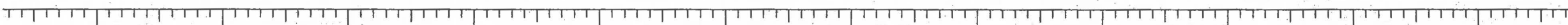

220

200

180

160

140

120

100

80

60

40

20

o ppm 


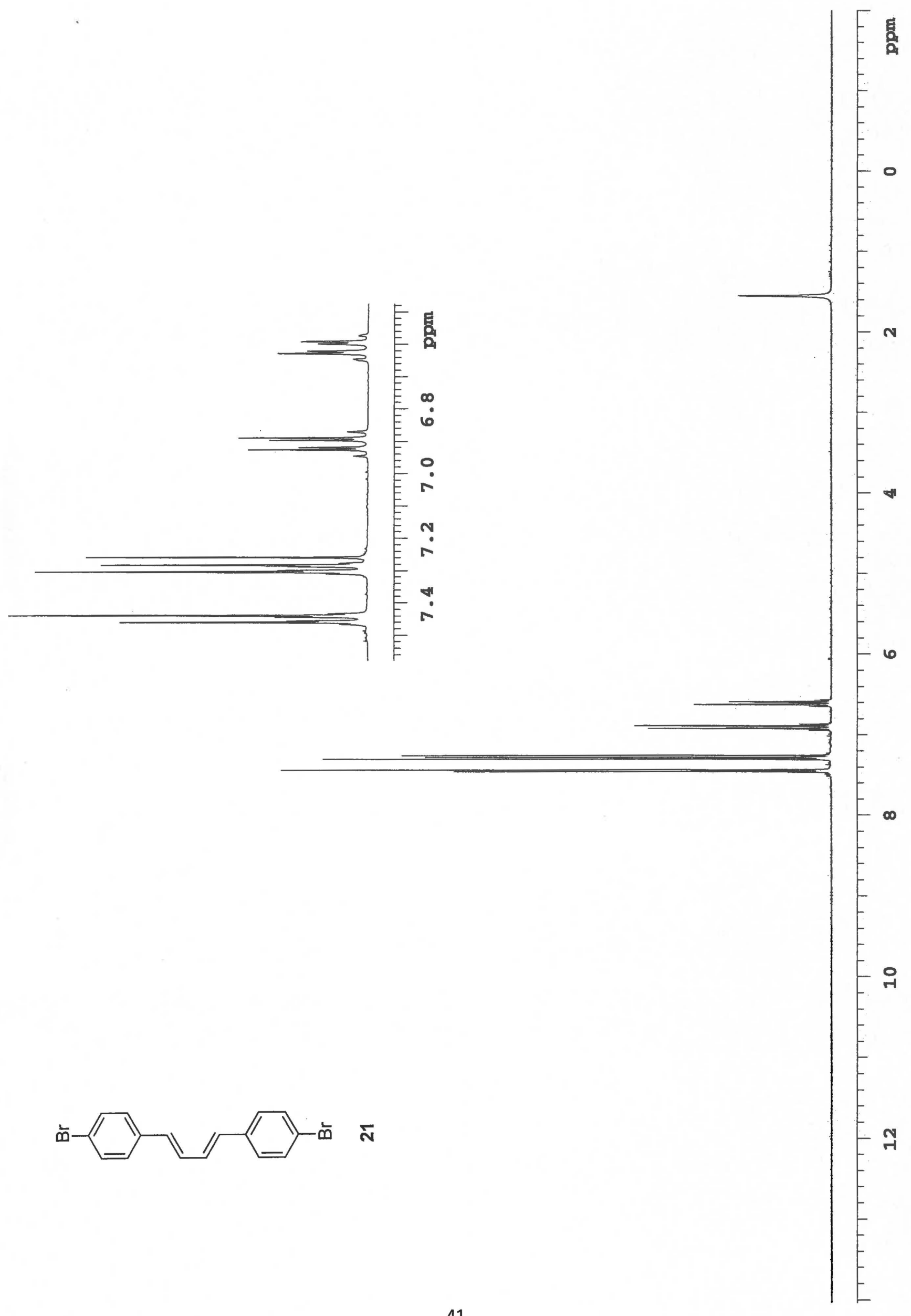




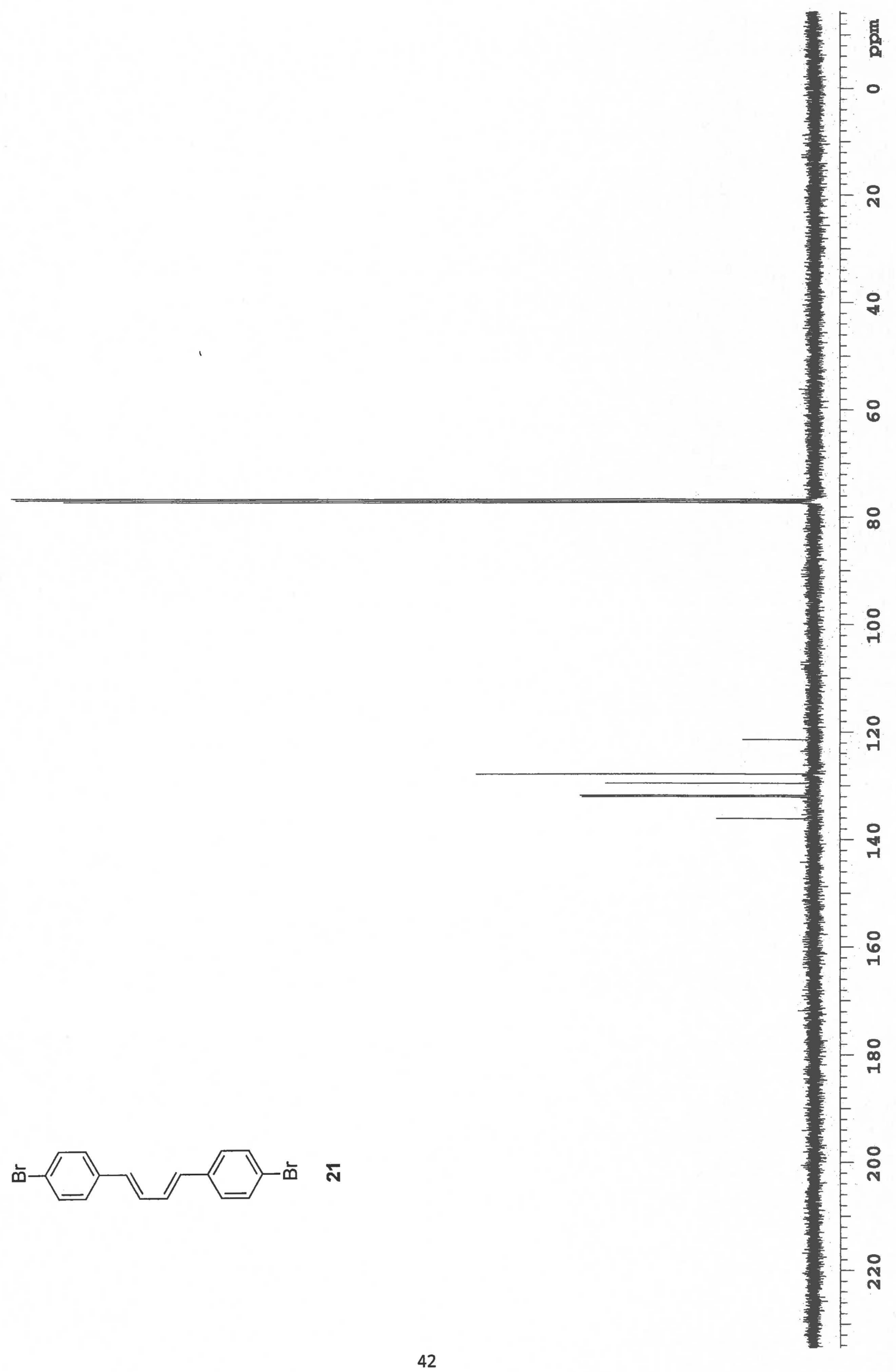



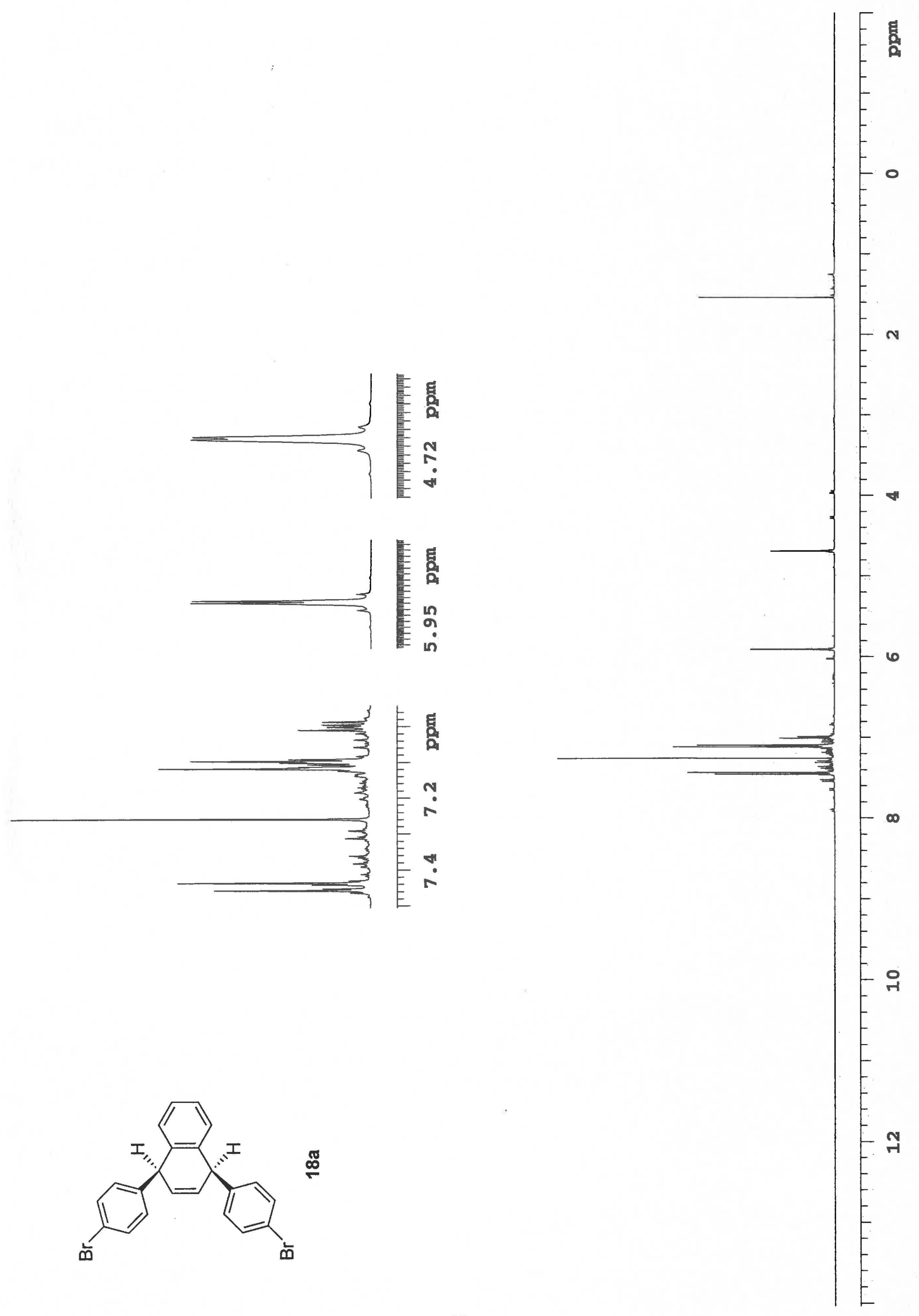


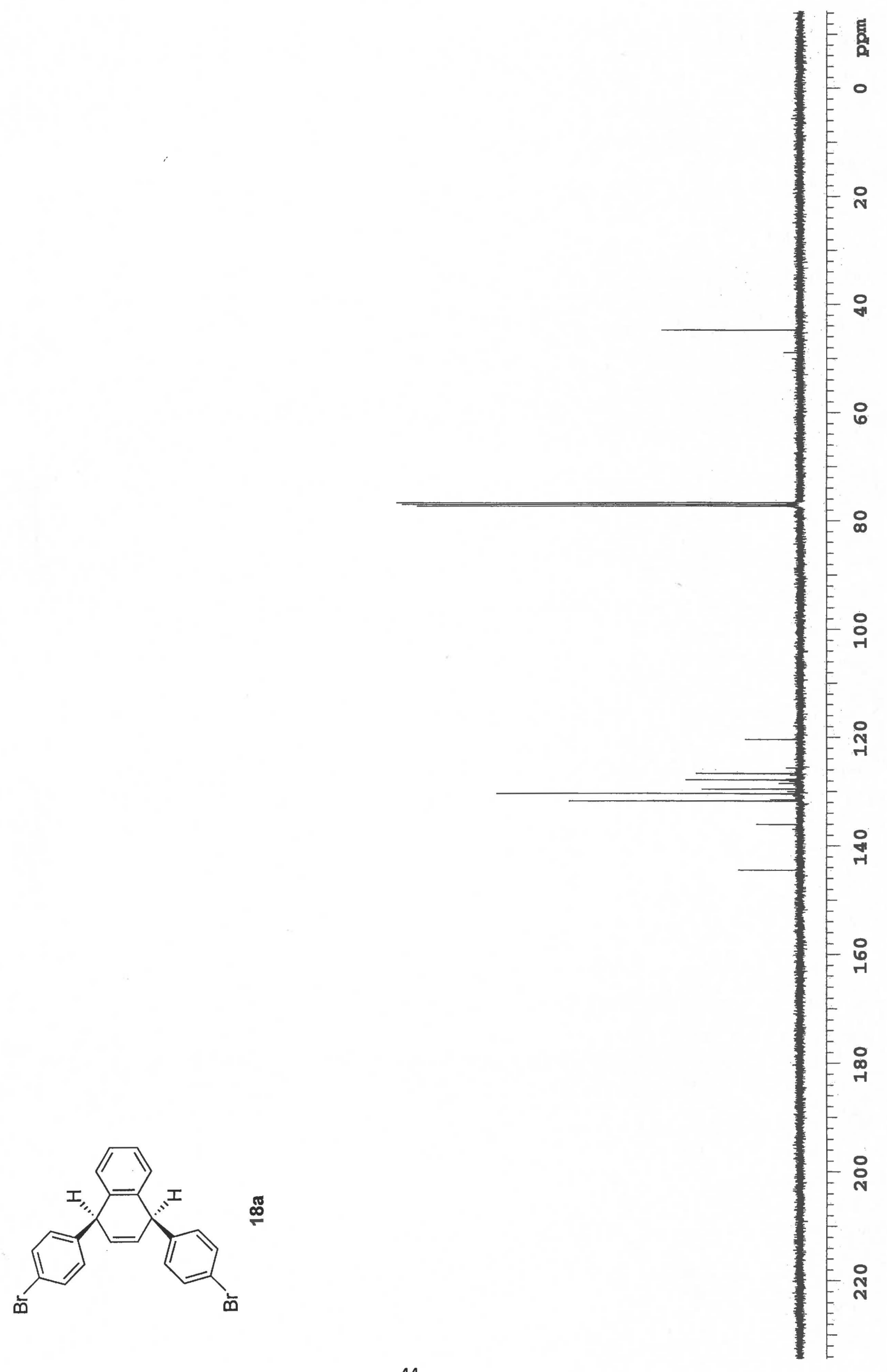



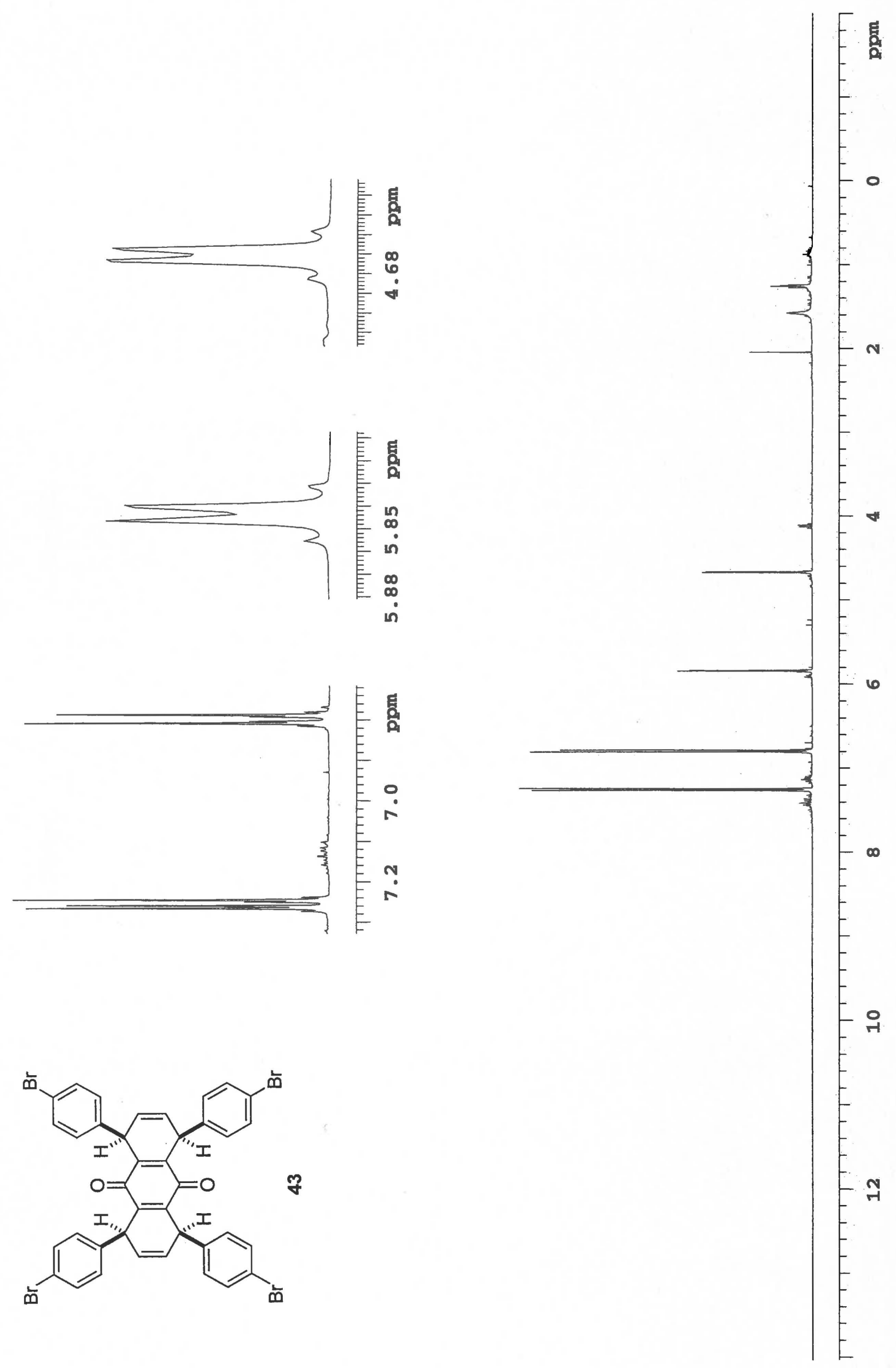


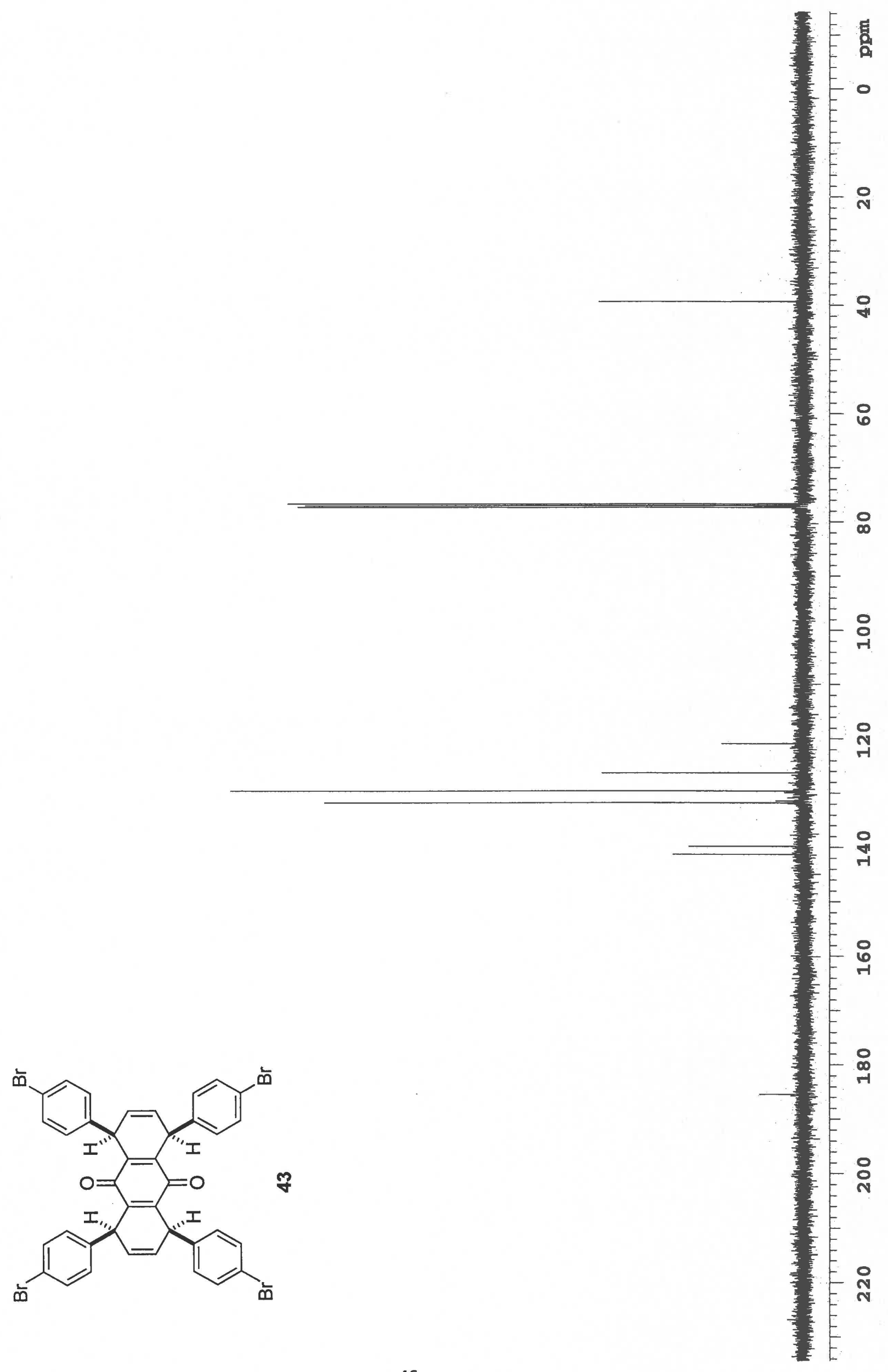



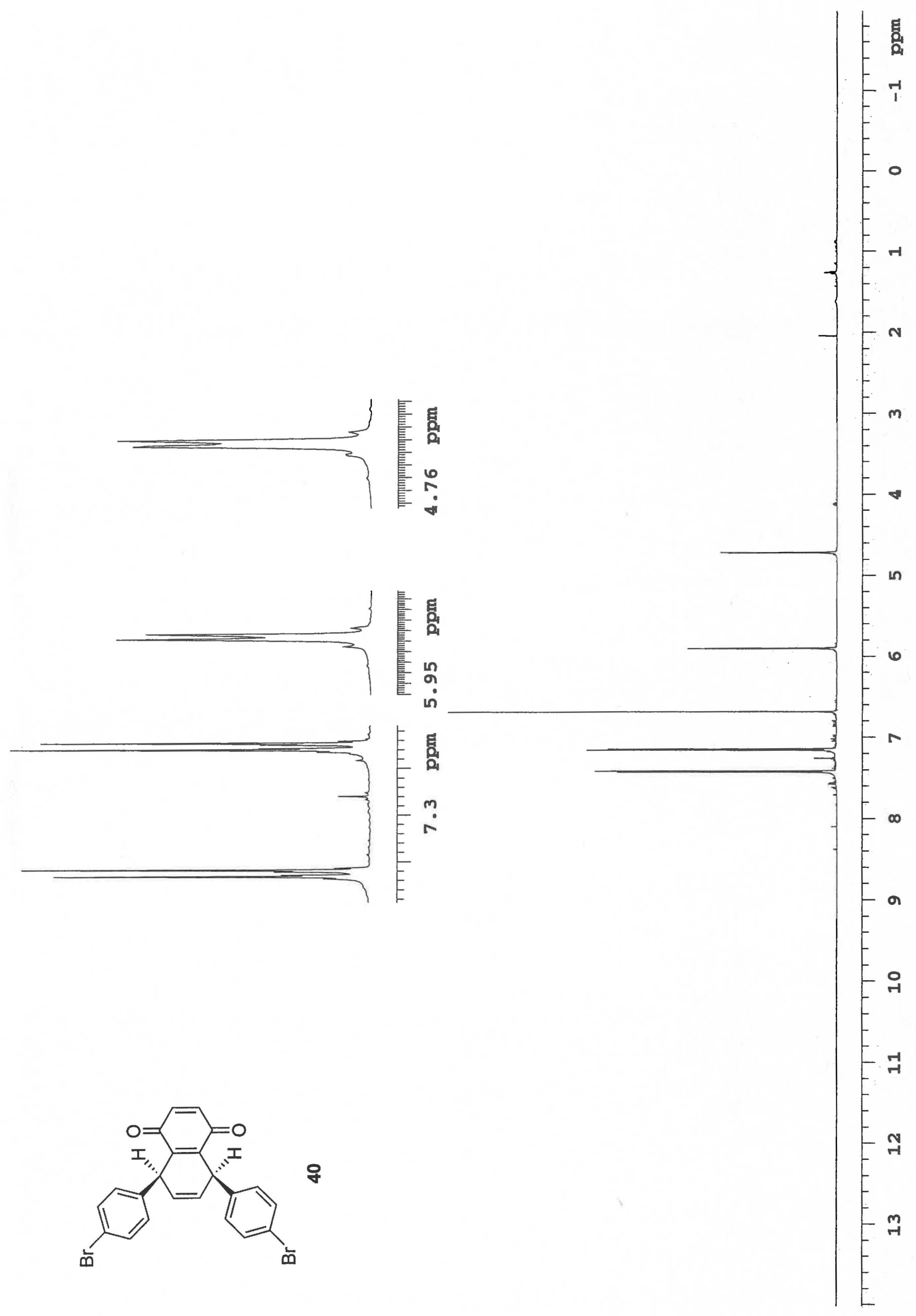


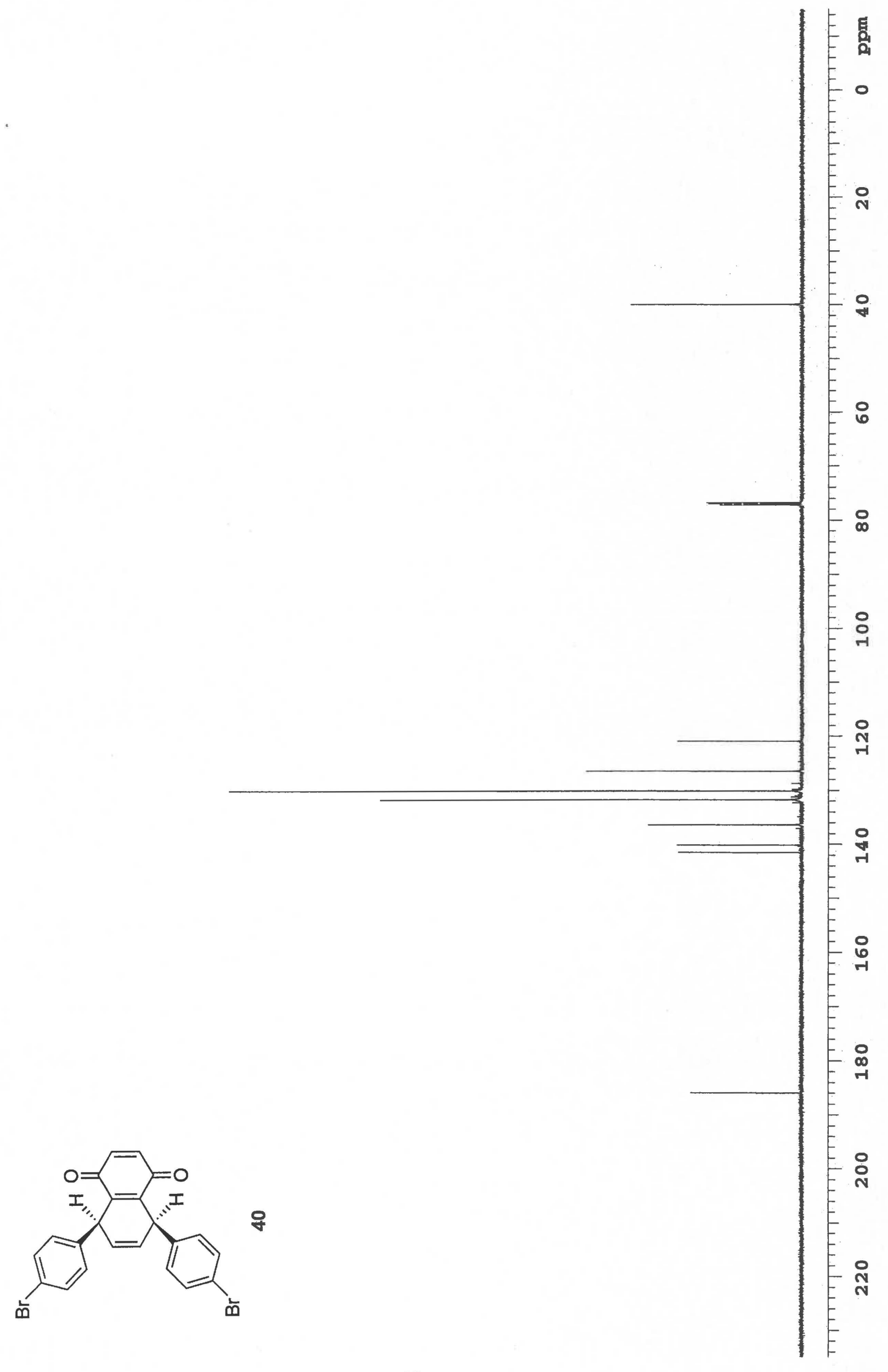




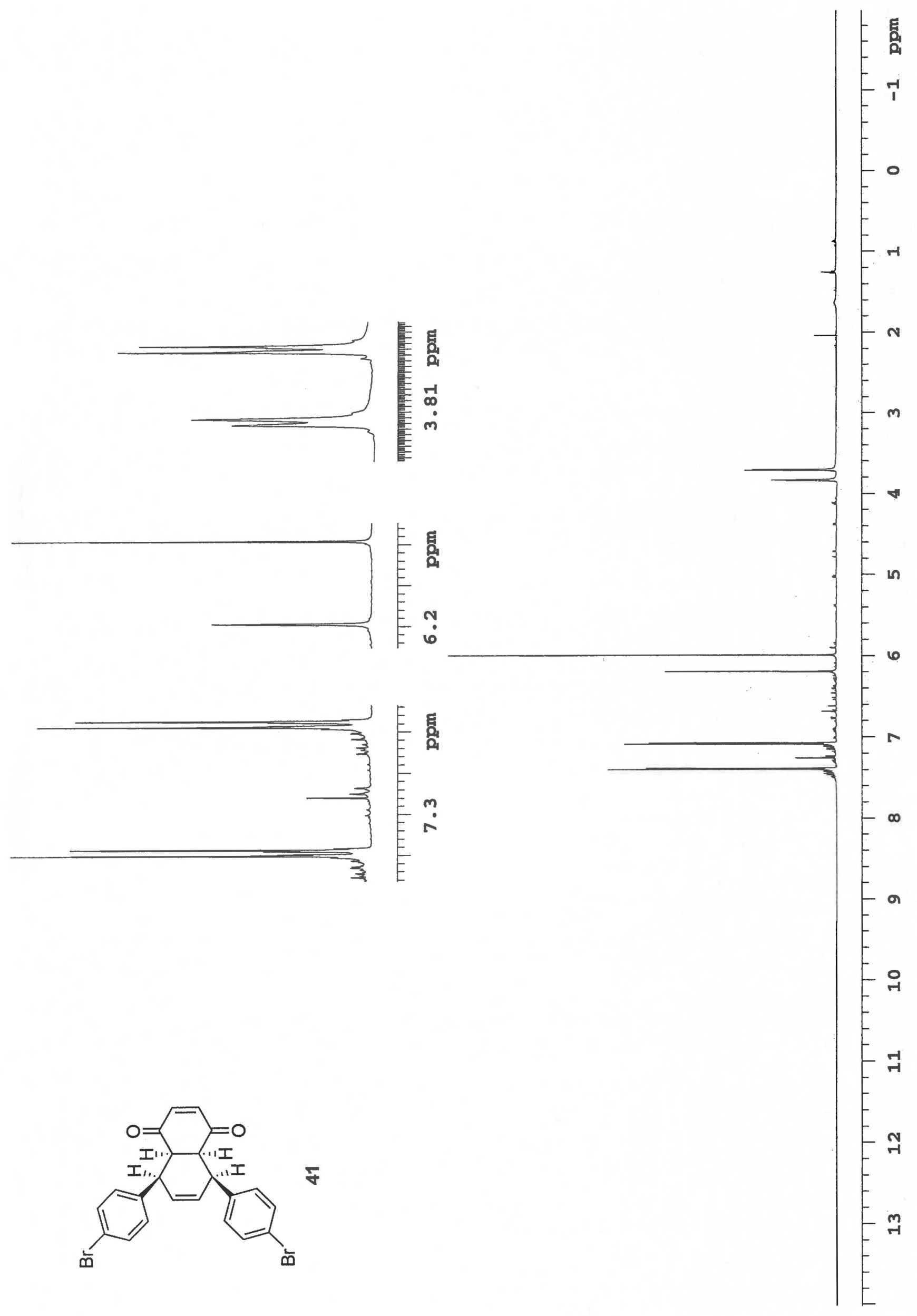




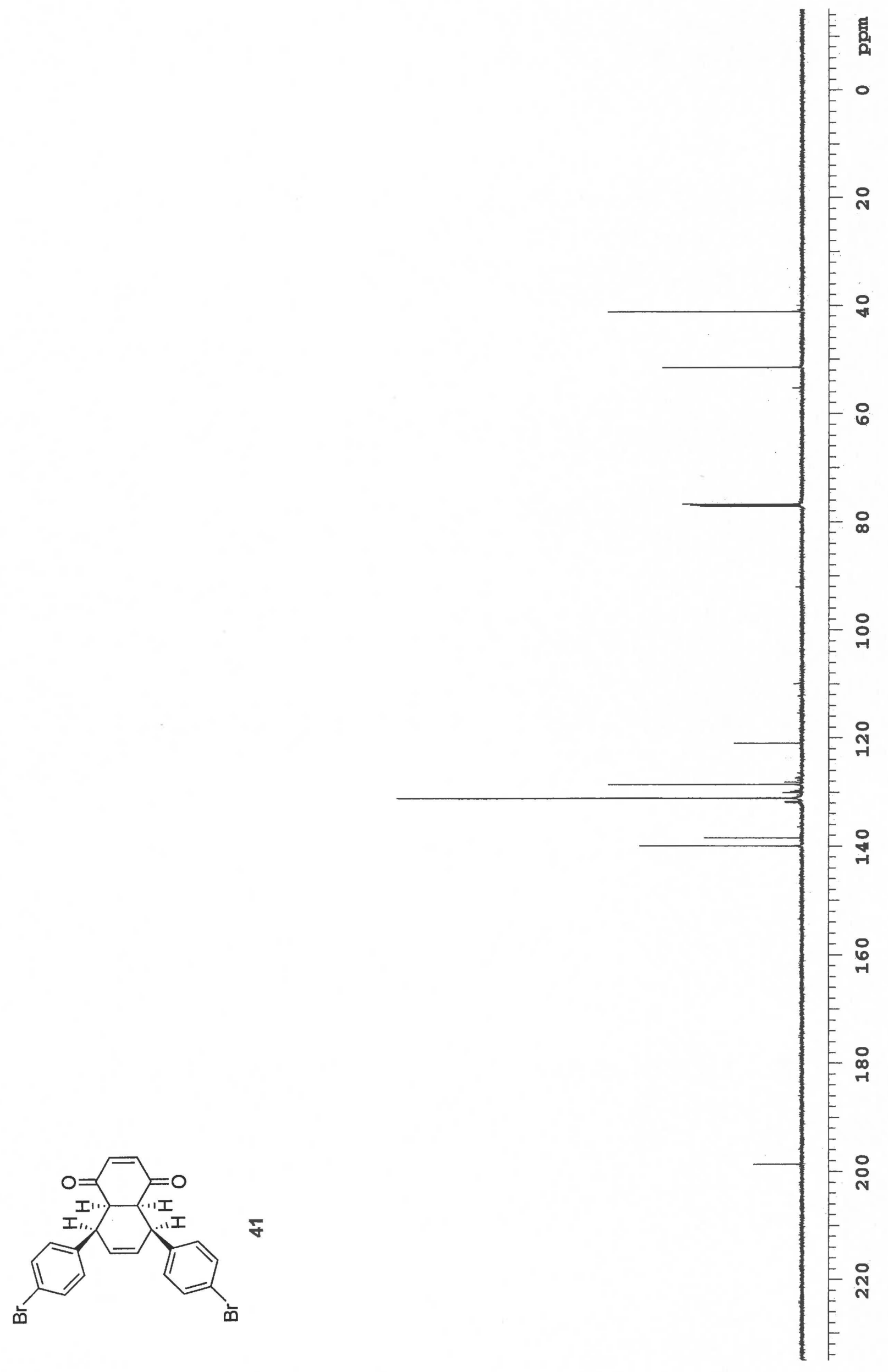




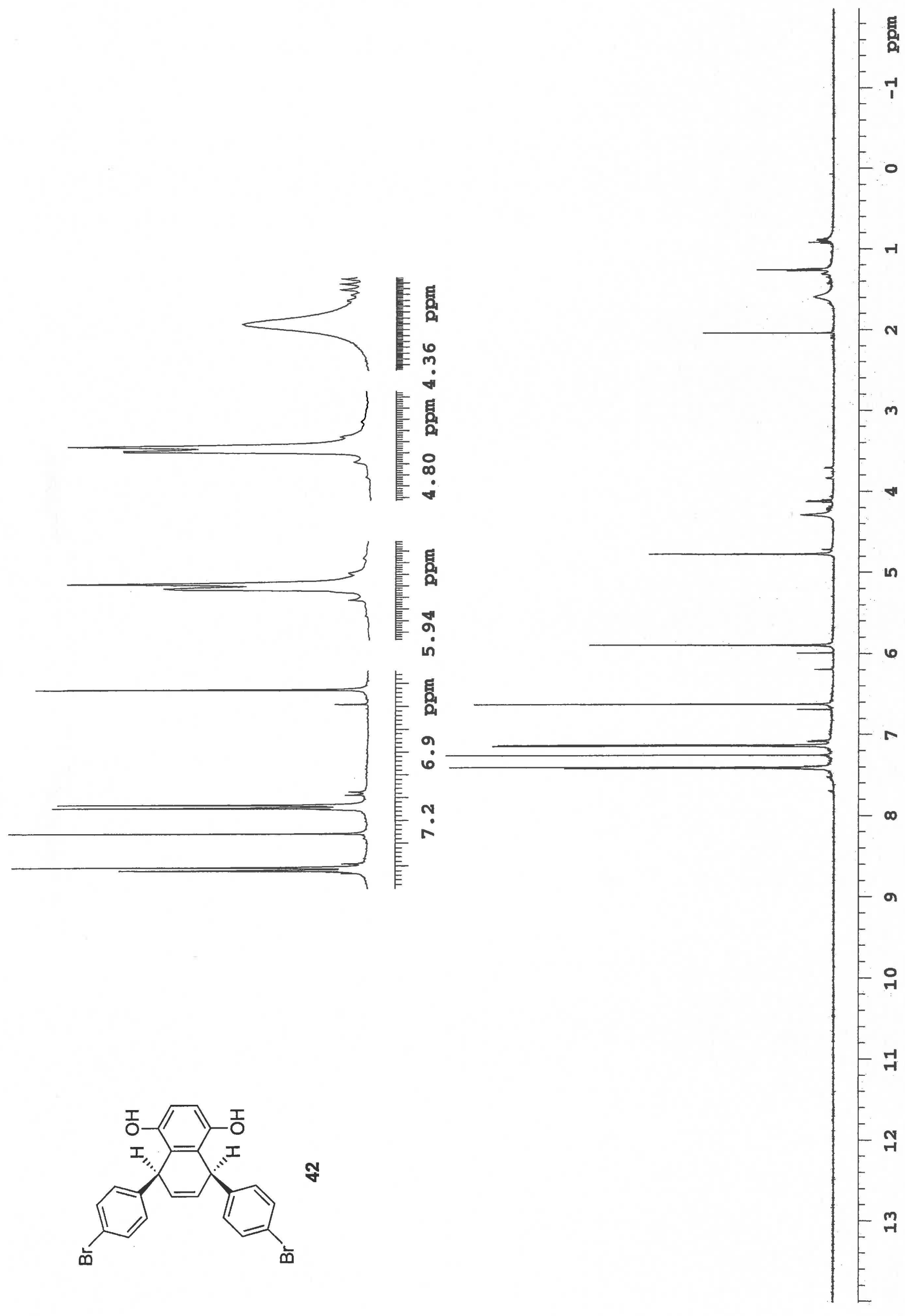




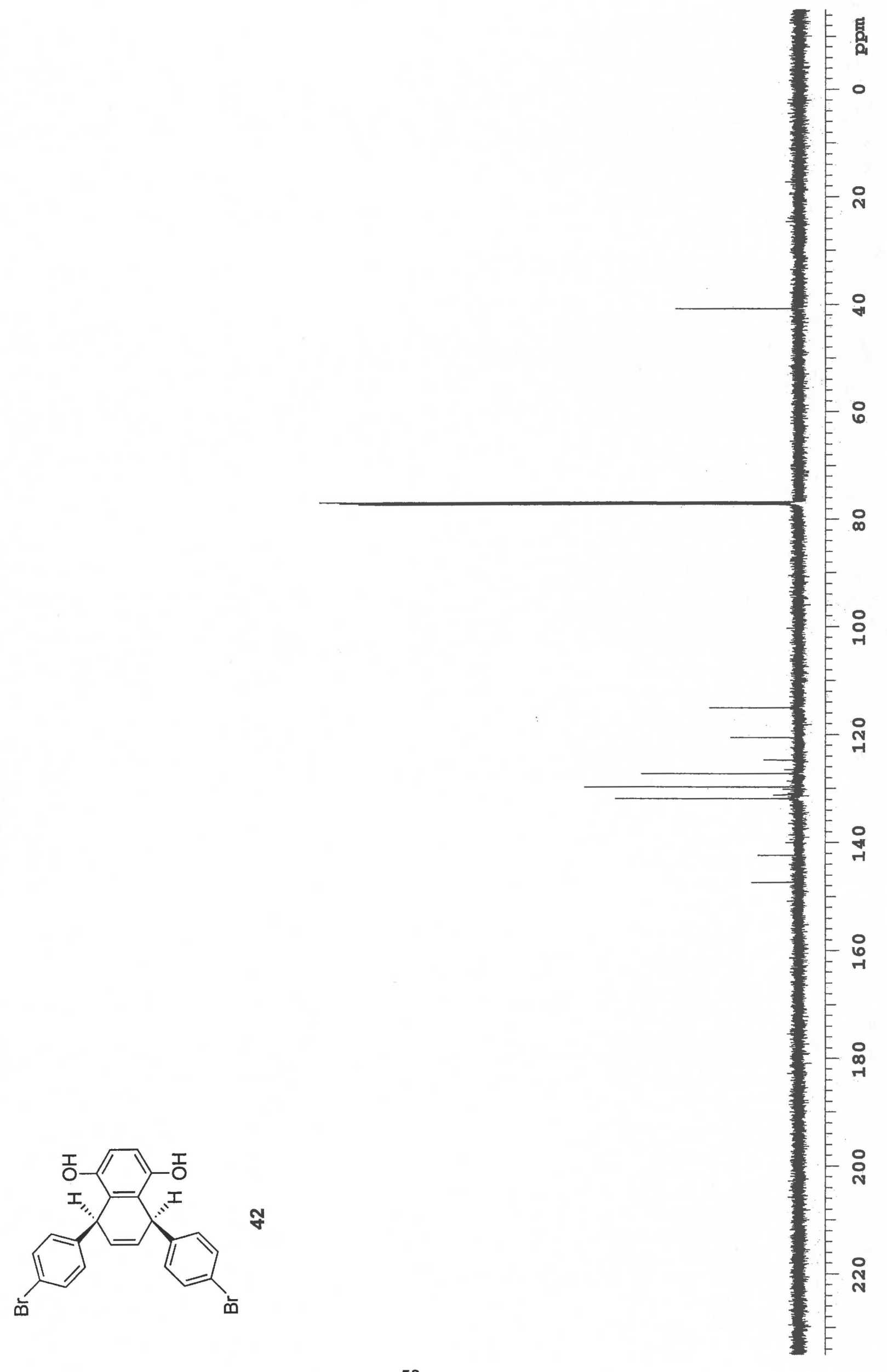




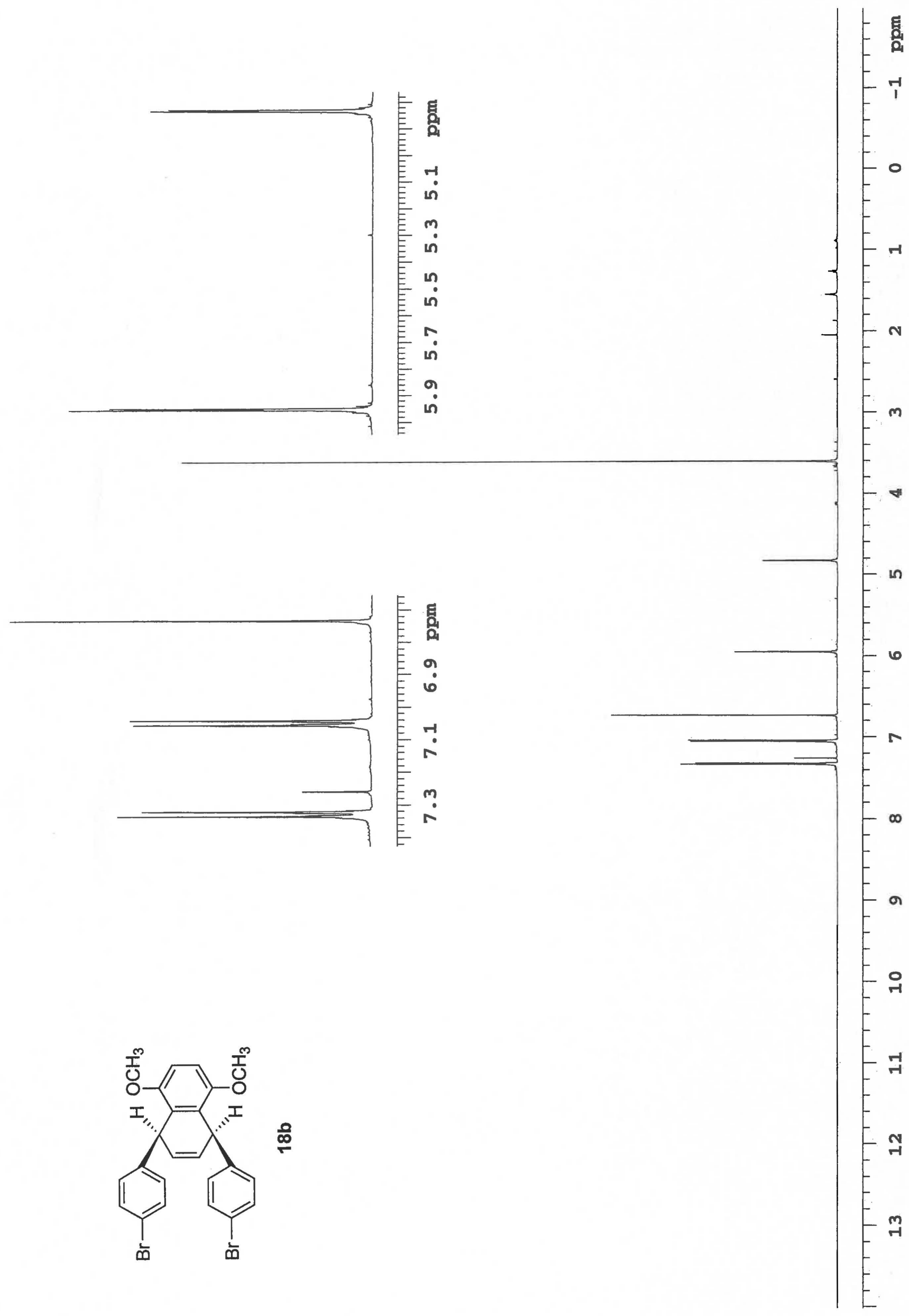




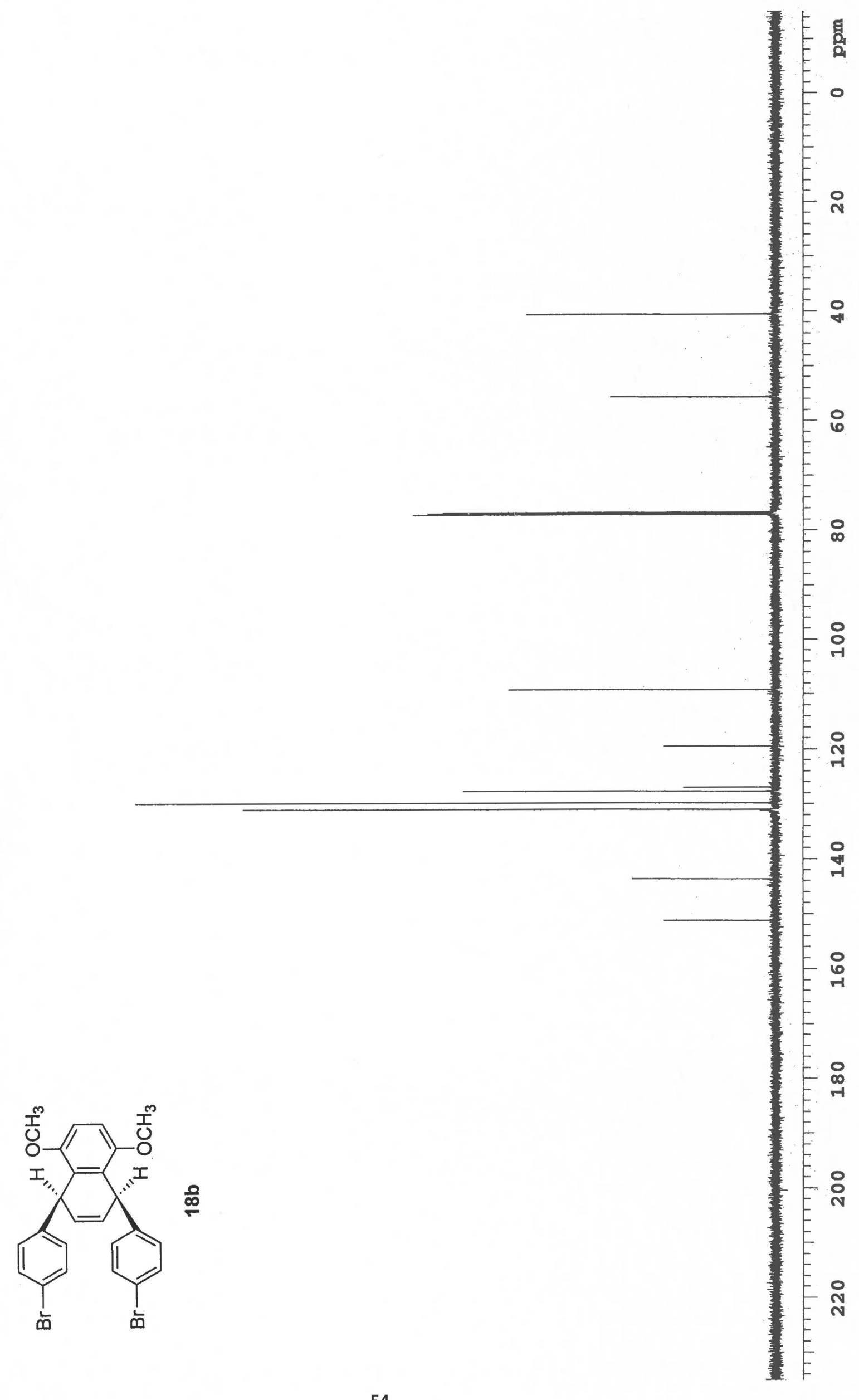




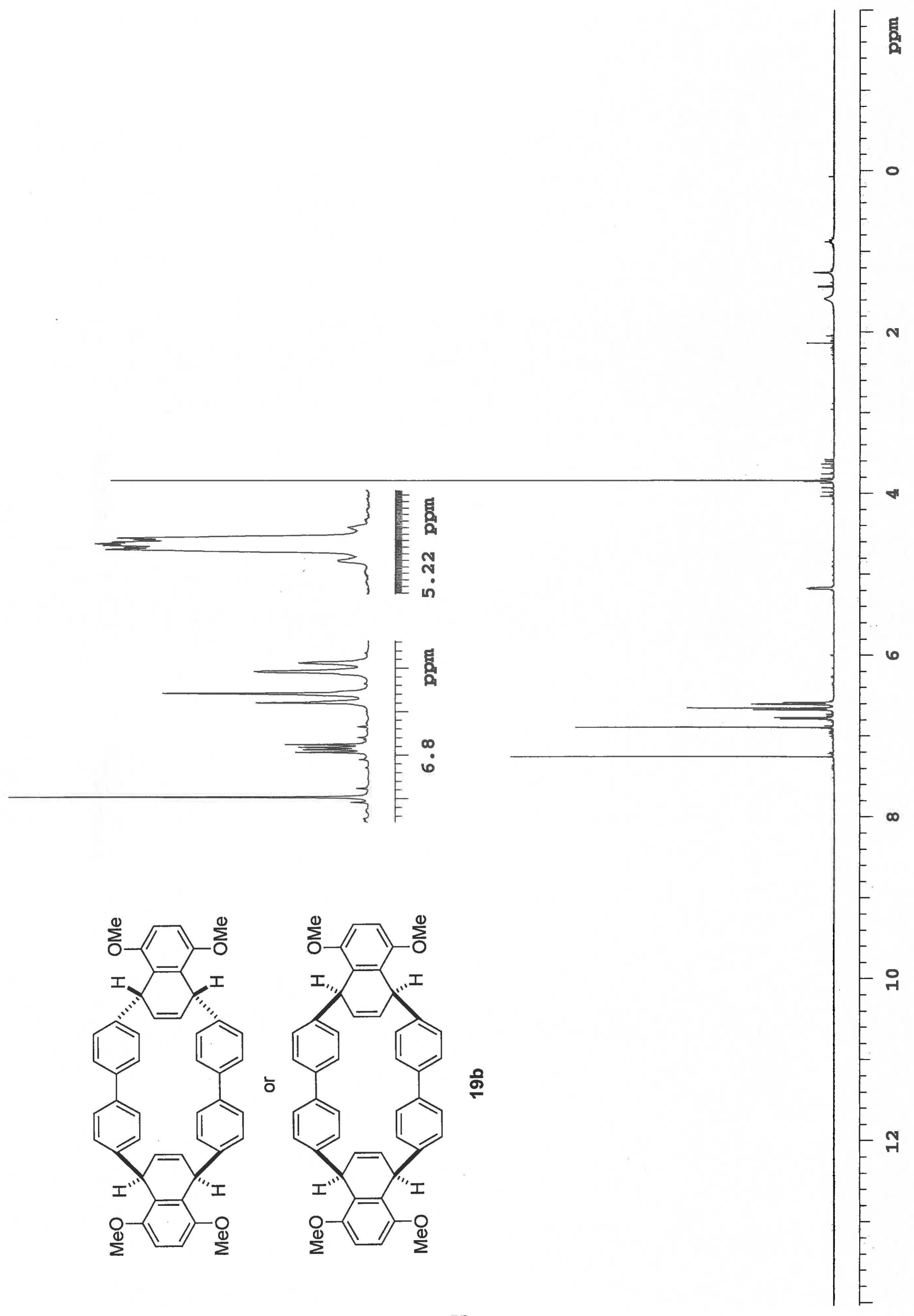




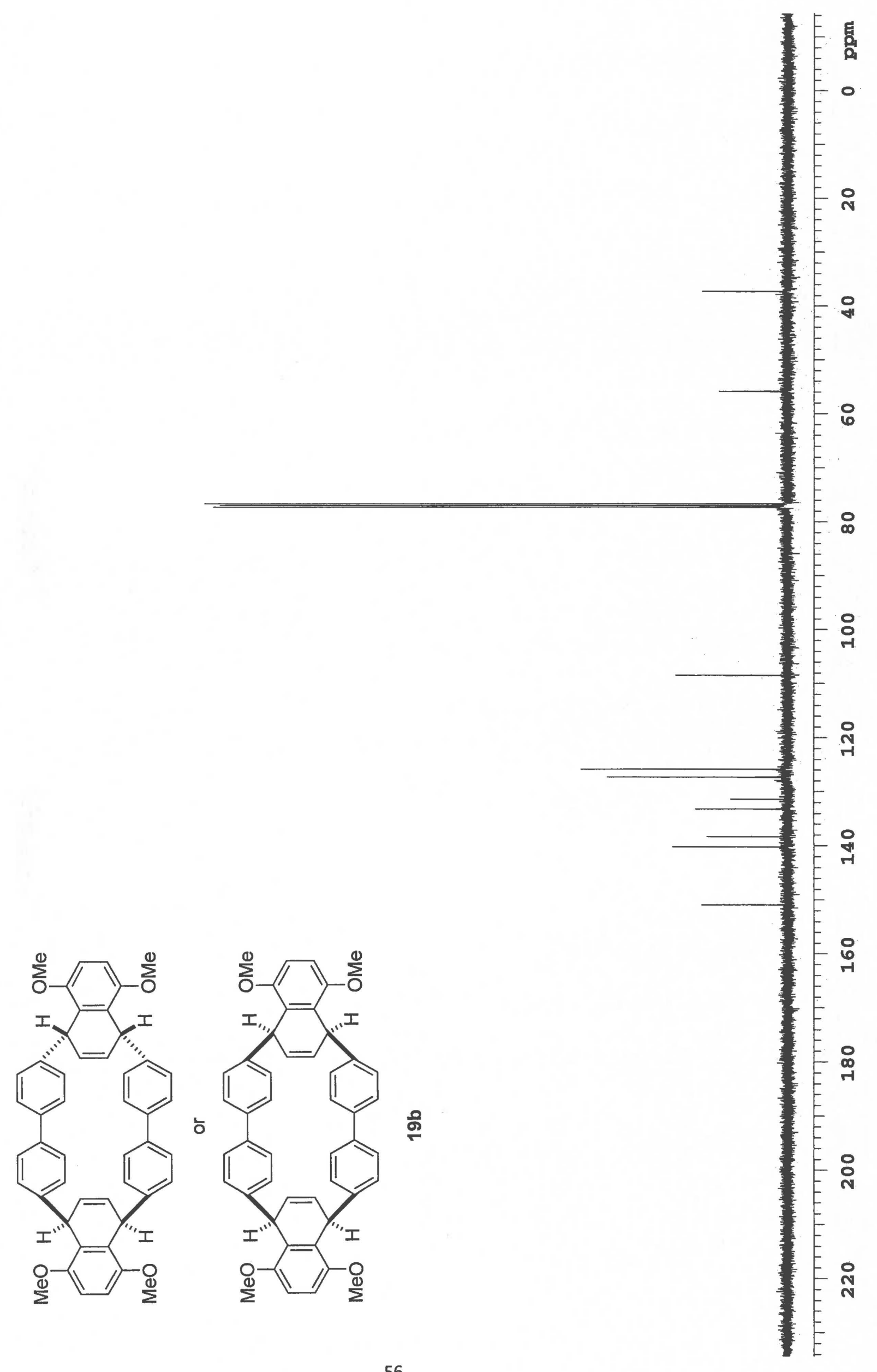




\title{
Development of Synthetic Pathways for Carbon Nanohoops
}

\author{
Yiwei Huang \\ Thesis submitted to the \\ Eberly College of Arts and Sciences \\ at West Virginia University \\ in partial fulfillment of the requirements \\ for the degree of
}

Master of Science

in

Chemistry

C. Eugene Bennett Department of Chemistry

APPROVAL OF THE EXAMINING COMMITTEE

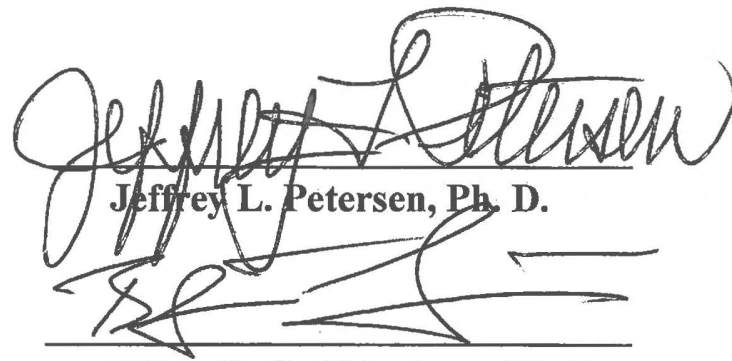

Björn C. G. Söderberg, Ph. D.

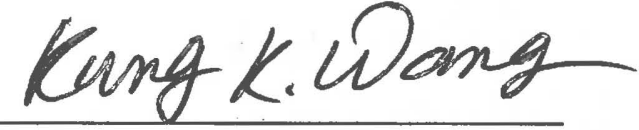

Kung K. Wang, Ph. D., Chair

$7 / 10 / 20 / 3$

Date 